\title{
Performance Enhancement of Metamaterial Loaded Micro Strip Patch Antenna Design Using Gallium Doped Ba-Sr Hexagonal Ferrite as Substrate Material for X-band Applications
}

\section{Monika Rani}

I K Gujral Punjab Technical University: IK Gujral Punjab Technical University Jalandhar kamal Jit bhatia ( $\sim$ kamalbhatia.er@gmail.com )

G B Pant Engineering College: Govind Ballabh Pant Institute of Engineering and Technology https://orcid.org/0000-0003-0363-0457

Harjitpal Singh

CTIEMT,Jalandhar

Harsimrat Kaur

CTIEMT, Jalandhar

Nancy Gupta

Khalsa College Lyallpur Institute of Management and Technology

\section{Research Article}

Keywords: Composite Material, S11 Parameter, Bandwidth, VSWR

Posted Date: June 4th, 2021

DOl: https://doi.org/10.21203/rs.3.rs-482118/v1

License: (c) (i) This work is licensed under a Creative Commons Attribution 4.0 International License.

Read Full License 


\title{
Performance Enhancement of Metamaterial Loaded Micro strip patch antenna design using Gallium doped Ba-Sr hexagonal ferrite as substrate material for $\mathrm{X}$-band applications
}

\author{
Monika Rani ${ }^{1} \cdot$ Kamaljit Singh Bhatia $^{2} \cdot$ Harjitpal Singh $^{3} \cdot$ Harsimrat Kaur $^{4}$. \\ Nancy Gupta ${ }^{5}$
}

\begin{abstract}
An experimental study of microstrip patch antenna designed and fabricated on FR4 epoxy substrate is presented. Further a performance comparison of designed antenna is made with proposed design using Gallium doped $\mathrm{Ba}-\mathrm{Sr}$ hexagonal ferrite substrate. Microstrip feed line is used for inputting the signal to antenna. The whole simulation is done on HFSS simulator (version 13.0). The center frequency for proposed antenna is $10 \mathrm{GHz}$ and is optimized for significant performance parameters viz return loss, bandwidth, VSWR and gain. It was observed that the designed antenna provides better results with ferrite substrate as compared to FR4 epoxy substrate showing $-10 \mathrm{db}$ broad bandwidth of $4.2 \mathrm{GHz}$ in the frequency region $8.2 \mathrm{GHz}$ to $12.4 \mathrm{GHz}$. Although, the results of other parameters like return loss, VSWR and gain are found to be optimum with FR4 substrate as compared to mentioned ferrite substrate. The prototype of proposed antenna with FR4 epoxy substrate is fabricated and tested to attain the experimental results. The measured results are found to be better than simulated results. Thus the proposed antenna structure can be considered suitable for microwave communication application in X-band..
\end{abstract}

Keywords Composite Material $\cdot$ S11 Parameter · Bandwidth · VSWR

Harsimrat Kaur

Simrat6@gmail.com

1 Department of Electronics and Communication Engineering, IKGPTU Kapurthala, Punjab, India

2 Department of Electronics and communication Engineering, G. B. Pant institute of Engineering \& Techonology, Pauri, Garhwal-246194, Uttarakhand, India

3,4 Department of Electronics and communication Engineering, CTIEMT, IKGPTU Kapurthala, Punjab, India

5 Department of Electronics and communication Engineering, LKCE, IKGPTU Kapurthala, Punjab, India 


\section{Introduction}

Due to small weight and size, the development in mobile communication continues to change day by day. For these handy devices in high speed communication system, small size antenna with wide frequency bandwidth is a major requirement. To meet this requirement, micro strip patch antenna design with partial ground structure is presented in this paper. As MSPA meets all requirements of wireless communication like low cost, high performance, compact size and low profile but has narrow bandwidth. To achieve broad bandwidth lots of techniques have been earlier adopted like use of stacked patches, frequency selective surfaces, Electronic Band Gap, Defected ground structure, metamaterials, photonic Band Gap, superstrate, using array of antenna and fractal antennas etc. as i have observed from the literature survey of various research papers in this field. Some researchers have also done experiment on changing the material of substrate of patch antenna to improve the performance parameters. Jeen Sheen Row et.al[1] has presented a short circuited triangular patch antenna and converted the UMTS and ISM bands successfully by achieving a bandwidth of more than $25 \%$ with total antenna height less than $0.06 \lambda 0$. Hamsakutty vettikalladi et.al[2] has designed microstrip patch antenna by adding superstrate and observed significant performance improvement of antenna as maximum gain of $14.6 \mathrm{dBi}$ with estimated efficiency of 76\%. Mohammed M.Bait-Suwailam et al.[3] have focused on bandwidth enhancement of a microstrip patch antenna Using Slotted-Complementary Split-Ring Resonators and observed 10dB reduction in the mutual coupling between two patch antennas with a separation of only $1 / 4$ free space wavelength between them. Lin Peng et al[4] has presented dual/triple band microstrip antenna with an asymmetric $\mathrm{M}$ shaped patch antenna usi ng vias. The antenna was fabricated at operating frequency $2.44 \mathrm{GHz} \& 5.77 \mathrm{GHz}$ and has not only achieved enhanced bandwidth but lesser cross polarization in $\mathrm{E}$ and $\mathrm{H}$ planes. Jieju Zhang et.al [5] has adopted electronic band gap structure to reduce the radar cross section of the patch array antenna. Approximate 10dB backward RCS was reduced with EBG at central frequency 5 GHZ. Elena Pucci et al.[6] has enhanced the Efficiency of Compact Patch Antennas Composed of Split-Ring Resonators by Using Lumped Capacitors. They have used double layer of low permittivity material with lower layer for feeding of antenna and upper layer with SRR and capacitor printed on top. With this design they observed $73 \%$ improvement in radiation efficiency at $1.29 \mathrm{GHz}$. R. Jothi Chitra et al [7] have tried to improve the Bandwidth, Radiation pattern return loss, VSWR on all the frequency bands of WiMAX and WLAN using an array of two rectangular patch antenna elements with two L-slots embedded on it and CPW feed is used to cover all frequency bands. M.A. Motin et.al [8] has designed an antenna with slot variations in patch for $\mathrm{K}$-band, $\mathrm{Ku}$ band and $\mathrm{X}$ band. Further they compared the performance using series feed array technique and found the return loss $-20 \mathrm{~dB}$ to $-25 \mathrm{~dB}$ at $19.5 \mathrm{GHz}$ and with series feed, return loss was $13 \mathrm{~dB}$ around at $21 \mathrm{GHz},-17.5 \mathrm{~dB}$ at $16 \mathrm{GHz}$ and -7.25 at $11.5 \mathrm{GHz}$. H. Vani et al [9] designed a novel MPA using a negative refractive index metamaterial in superstate and observed an improvement in gain by $2.64 \mathrm{~dB}(119 \%)$ at frequency band 935MHz to $960 \mathrm{MHz}$. Further Arvind Kumar et. al [10] has tried to enhance the gain of antenna using square microstrip patch with $\mathrm{U}$ slot using metallic rings at $5.8 \mathrm{GHz}$ and has achieved $4.3 \mathrm{~dB}$ enhancement in gain as compared to antenna without metallic rings. Wangwang han et. al [11] has presented a single feed circularly polarized microstrip antenna with epsilon negative transmission line based annular ring at $5.25 \mathrm{Ghz}$ and obtained an overlapped bandwidth (RL<-10dB and $\mathrm{AR}<3 \mathrm{~dB}$ ) of $4 \%$ which is 2.3 times greater than conventional circularly polarized microstrip antenna. Situ Rani Patre et al [12] has designed CPW fed flower shaped patch antenna i.e a modified version of circular patch and achieved wider VSWR bandwidth due to larger perimeter and smaller boundary segments of flower shaped patch as compared to circular patch. Muhammad Saqib Rabbani et al [13] have proposed an antenna designed with very low cost PCB substrate and has two rectangular slits joined by a metallic slit. The antenna design was fabricated using low cost PCB etching method and tested at X-band and 60GHz band. Amit A. Deshmukh et al [14] has designed a Broadband Slot cut Rectangular Microstrip Antenna with unequal length rectangular slots of $\mathrm{E}$ shaped patch. They observed broadside radiation pattern of antenna with peak gain of more than $8 \mathrm{dBi}$ and wide $\mathrm{BW}$ as compared to normal E shaped patch antenna. Xiang-Jun Gao et al [15] have tried to enhance the gain and directivity for microstrip antenna using negative permeability metamaterial of Dual layer symmetry single ring resonator pair embedded(D-SSRRP) on both sides of dielectric layer in MSPA at $5.2 \mathrm{GHz}$ and $6.75 \mathrm{GHz}$ center frequencies. With such an addition in structure of antenna, the gain was increased upto $2.2 \mathrm{~dB}$ and antenna half power beam width was decreased upto 200 comparatively. Guirong Feng et al [16] have presented a broadband surface wave antenna using a non-uniform tapered microstrip antenna with smaller inner rectangular patches on dielectric substrate and achieved a wide BW of $33.1 \%(4.56 \mathrm{GHz}-6.37 \mathrm{GHz})$ for a low profile antenna of $0.06 \lambda 0$ and has an average gain of $6.34 \mathrm{dBi}$. Yanwen Hu et al [17] have tried to improve the gain and directivity of linear polarized antenna by placing a chiral metamaterial board of $5 \times 5$ unit cells in front of LP patch antenna to convert to circular polarization. Shobhit Kumar Patel et al [18] have proposed metamaterial inspired microstrip patch antenna having the capability of tuning the frequency spectrum and beam radiation. The tuning is possible by placing MEMS switches between the gap on SRRs. Gohar Vermini et al [19] have also tried to miniaturize the microstrip antenna using metasurfaces designed with number of parrellel rings. The size of antenna got drastically reduced with good gain $\mathrm{n}$ return loss as frequency shifts from $7 \mathrm{GHz}$ to $4 \mathrm{GHz}$. Zhen-Zhong Yang et al [20] have proposed wideband, low-profile, and 
high-gain antenna loaded with a dual-layer metasurface printed on two dielctric layers and achieved $44 \%$ impedance bandwidth and $45 \%$ gain bandwidth with peak gain of 11.6dBi. Nancy Gupta et al [21] have proposed design of wideband diagonally symmetrical flower shaped patch antenna and achieved wide impedance bandwidth between $1.49 \mathrm{GHz}$ and $2.46 \mathrm{GHz}$.

The literature discussed above have mostly tried to make changes in patch and improved the limitations of MSPA but some researchers have done experiment with the change of material of dielectric substrate irrespective of FR4 and RT/Duroid. They found that with the change in properties of dielectric material like permittivity, permeability, tensile strength etc., the antenna parameters get improved. Debashis Sarmah et al [22] have proposed MSPA designed on LDPE/Tio2 substrate and found it suitable for X-Band applications. Naveen kumar sexena et al [23][24] have designed MSPA on LiTiZn and LiTiMg ferrite substrate and found improved radiation characteristics and performance parameters with less surface wave losses. Sanjay. R. Bhongale et al [25] have prepared Mg-Cd ferrite substrate using microwave sintering technique and used it as a dielectric substrate in MSPA and better results of VSWR, Bandwidth and return loss. Intan Helina Hasan et al [26] have proposed a MSPA designed on thick layer of Yttrium iron garnet (YIG) deposited on FR4 epoxy substrate and and found enhancement in performance parameters of antenna. Sanjay. R. Bhongale [27] have proposed another MSPA using Mg-Nd-Cd ferrite substrate and showed the improvements in return loss, VSWR and bandwidth making it suitable for X-Band applications.

Following the literature survey, we have also designed a novel Microstrip patch antenna with number of parallel rings in the structure of patch and compared the results using FR4 epoxy substrate and innovatively composed/synthesized Gallium doped $\mathrm{Ba}-\mathrm{Sr}$ hexagonal ferrite substrate of antenna. This antenna operates in X-band frequency range. We have used Microstrip line feed for giving input to antenna. The design is simulated using HFSS with version 13.0. Firstly the design of antenna is discussed below with ferrite substrate following the discussions $n$ comparison of results with both types of substrates. The antenna is fabricated on FR4 substrate and then measured and simulated results are compared in next section. In the last, results are concluded based on the discussions.

\section{Materials and Methods}

\section{Materials}

As our main goal was to design an antenna with enhanced bandwidth to be compatible for X-band application, so to achieve this, we have used four split ring resonators placed complement to each other. To further enhance the bandwidth, partial ground plane is used here. We have taken a substrate of $38 \times 28 \times 1.575 \mathrm{~mm} 3$ with dimensions of ground plane as $10 \times 28 \mathrm{~mm} 2$. The microstrip feed line is used to deliver input to proposed antenna. The dimensions of feed line are $12 \times 2 \mathrm{~mm} 2$. Initially, we have designed the proposed antenna on commercially available FR4 epoxy substrate material having dielectric loss i.e. $\tan \delta$ of 0.02 and permittivity of 4.4. As, four MTM cells are used in the layout, the dimensions of outer and inner ring of first SRR is 22x20 mm2 and 20x18 mm2 respectively. All four MTM cells have a gap of 1mm each. Figure 2(a) shows the top view of structure showing patch, substrate and feed line and figure 2(b) shows the partial ground plane. The full dimensions of antenna structure are mentioned in table 1 given below.

\section{Preparation of doped M-Type Ferrite}

In addition to this, the novelty of this research is that the proposed design is also simulated with synthesized /composed Gallium doped $\mathrm{Ba}-\mathrm{Sr}$ hexagonal ferrite substrate which is presented by chemical formula $\mathrm{Ba}_{0.5} \mathrm{Sr}_{0.5} \mathrm{Co}_{\mathrm{x}} \mathrm{Ga}_{\mathrm{x}} \mathrm{Fe}_{(12-2 \mathrm{x})} \mathrm{O}_{19}$ with $(\mathrm{x}=0.2,0.4,0.6,0.8,1.0)$. The ferrite substrate is composed based on solid state reaction (standard ceramic method) \& sintered in microwave furnace at $11000 \mathrm{C}$ temperatures. 


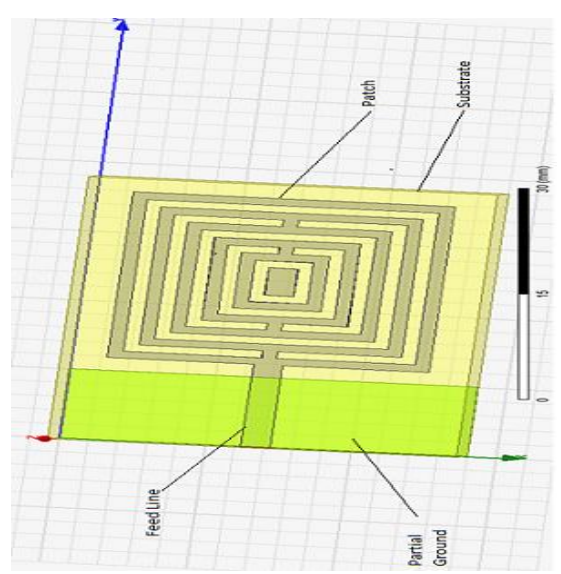

(a)

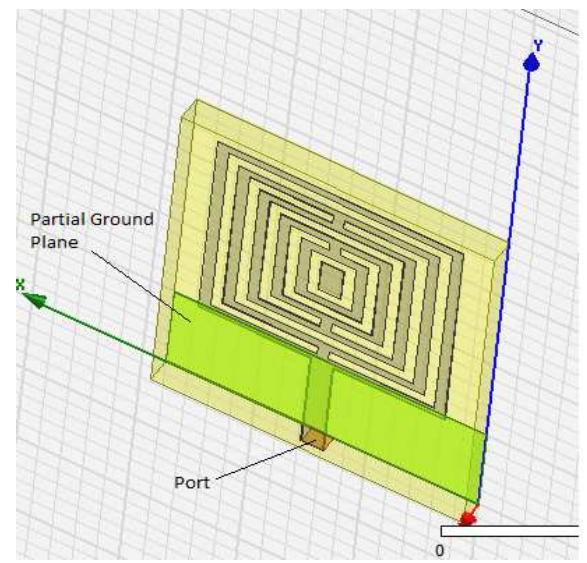

(b)

Figure 1 Software design Layout of proposed antenna (a) Top view (b) Bottom view

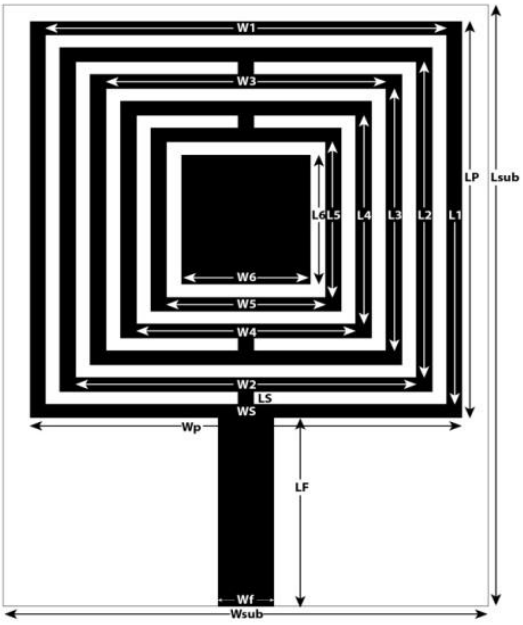

(a)

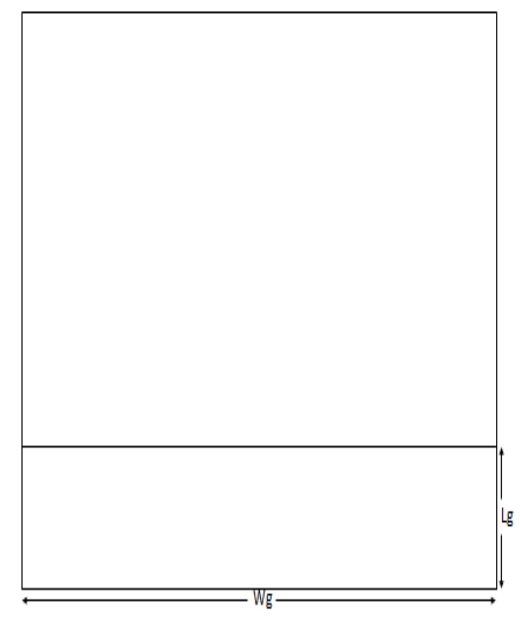

(b)

Figure 2 Structure of proposed antenna design (a) Front view (b) Back view

From the literature survey, it is being observed that microwave absorbing properties of composite ferrite material vary with doping concentration and found to be good absorber at low doping [28]. So, we can achieve bandwidth enhancement by varying this. Further, according to a zero order analysis suggested earlier by Hansen \& Burkey [29], bandwidth of patch antenna can be enhanced by using magneto-dielectric material for substrate as the zero order bandwidth is given as

$\mathrm{BW}=\frac{96 \sqrt{\frac{\mu}{\varepsilon}}}{\sqrt{2[4+17 \sqrt{\mu \varepsilon}]}} \frac{t}{\lambda_{o}}$

Where $\mu=$ permeability of material, $\varepsilon=$ permittivity of material, $\mathrm{t}=$ thickness of material. This equation suggests that with the variation of parameters of material, large bandwidth enhancement is possible and it is being validated in the research done by H. Kaur et.al [28]. She has synthesized a M-type Ba-Sr hexagonal ferrite with varying doping concentration $\mathrm{Co}^{2+}$ $\& \mathrm{La}^{3+}$ ions. She has observed a reflection loss of $-43.33 \mathrm{~dB}$ with $\mathrm{x}=0.2$ doping concentration at frequency $10.75 \mathrm{GHz}$. That means, ferrite materials are very much suitable to be used as substrate for microstrip patch antenna design.

Table 1 Geometrical parameters for designed antenna

\begin{tabular}{|c|c|c|c|}
\hline $\begin{array}{l}\text { Geometrical } \\
\text { Parameters }\end{array}$ & $\begin{array}{l}\text { Dimensions } \\
(\mathrm{mm})\end{array}$ & Geometrical Parameters2 & $\begin{array}{l}\text { Dimensions } \\
(\mathrm{mm})\end{array}$ \\
\hline Lsub, substrate length & 38 & $\begin{array}{l}\mathrm{W}_{\mathrm{s}} \text {, width of separation } \\
\text { between rings }\end{array}$ & 1 \\
\hline $\mathrm{W}_{\text {sub}}$, substrate width & 28 & $\mathrm{~L}_{2}, \mathrm{SRR} 2$ outer ring length & 18 \\
\hline
\end{tabular}




\begin{tabular}{|llll|}
\hline $\mathrm{h}$, substrate height & 1.575 & $\mathrm{~W}_{2}$, SRR2 outer ring width & 16 \\
\hline $\mathrm{L}_{\mathrm{f}}$, feed length & 12 & $\mathrm{~L}_{3}$, SRR3 outer ring length & 14 \\
\hline $\mathrm{W}_{\mathrm{f}}$, feed width & 2 & $\mathrm{~W}_{3}$, SRR3 outer ring width & 12 \\
\hline $\mathrm{L}_{\mathrm{p}}$, patch length & 24 & $\mathrm{~L}_{4}$, SRR4 outer ring length & 10 \\
\hline $\mathrm{W}_{\mathrm{p}}$, patch width & 22 & $\mathrm{~W}_{4}$, SRR4 outer ring width & 8 \\
\hline $\begin{array}{l}\mathrm{L}_{\mathrm{g}}, \text { partial ground plane } \\
\text { length }\end{array}$ & 10 & $\mathrm{~L}_{5}$, inner rectangle1 length & 6 \\
\hline $\begin{array}{l}\mathrm{L}_{1}, \text { SRR1 outer ring } \\
\text { length }\end{array}$ & 22 & $\mathrm{~W}_{5}$, inner rectangle1 width & 4 \\
\hline $\begin{array}{l}\mathrm{W}_{1}, \text { SRR1 outer ring } \\
\text { width }\end{array}$ & 20 & $\mathrm{~L}_{6}$, inner rectangle2 length & 4 \\
\hline $\begin{array}{l}\mathrm{L}_{\mathrm{s}}, \text { length of separation } \\
\text { between rings }\end{array}$ & 1 & $\mathrm{~W}_{6}$, inner rectangle2 width & 2 \\
\hline
\end{tabular}

\section{Results and Discussion}

The MTM cell based antenna design is initially simulated with FR4 epoxy substrate and then with Gallium substituted $\mathrm{Ba}-\mathrm{Sr}$ hexagonal ferrite substrate material in X-band frequency range i.e.8.2-12.4GHz using HFSS version 13.0 simulator. We analyzed the proposed antenna design using both substrates. The overall analysis is made on Reflection coefficient (S11), VSWR, gain and radiation pattern. S11 gives the relationship between input and output ports of an electrical framework. With this parameter, we determine the quality of transmission in regards to impedance matching between transmission end (source) and receiving end (load). The value of S11 must be below $-10 \mathrm{~dB}$ for quality communication. In case of any mismatching at the port, the signal can be reflected back from feedpoint \& will not be radiated by antenna. The radiation pattern defines the variation of power radiated by an antenna as a function of direction away from antenna. It represents the variation of signal strength by designed antenna w.r.t horizontal and vertical angles at certain resonant frequency for far field on two planes referred as Eplane (Phi-90 degree) \& H-plane (Phi-0 degree). There is another very important parameter i.e. Voltage standing wave ratio (VSWR). It shows the quantity of mismatch between antenna and port. Its acceptable value is between $1 \& 2$. The ideal value of VSWR is 1 .We are describing below the results of simulation of proposed antenna design for both FR4-epoxy and Gallium substituted Ba-Sr hexagonal substrates.

\section{FR4 glass epoxy material}

FR4 stands for flame retardant glass epoxy material. It is a NEMA grade designation for glass reinforced epoxy laminate material. It is basically a very popular and versatile high pressure thermoset plastic laminate grade with good strength to weight ratio $\mathrm{n}$ have bromine and halogen to facilitate flame resistant properties. Firstly, we have simulated the proposed antenna design using FR4 substrate material and observed the performance with some important parameters in X-band $(8.2-12.4 \mathrm{GHz})$ frequency range. The simulation results of return loss, bandwidth and VSWR are given below in the table 2.

Table 2 Simulated results with FR4 material

\begin{tabular}{cccc}
$\begin{array}{c}\text { Resonan } \\
\mathbf{t}\end{array}$ \\
$\begin{array}{c}\text { Frequen } \\
\text { cy }(\mathbf{G H z})\end{array}$ & $\begin{array}{c}\text { Return Loss } \\
(\mathbf{d B})\end{array}$ & VSWR & Bandwidth \\
\hline & & 1.978207 & \\
10.888 & -18.9089 & 0.291424 & $(12.4-10.531) \mathrm{GHz}=1.869 \mathrm{GHz}$ \\
\hline 12.316 & -35.5072 & & \\
\hline
\end{tabular}

In the results shown above, figure 3(a) shows the simulation graph of return loss using FR4 substrate material. We have made comparison of results with desired $-10 \mathrm{~dB}$ line of return loss in the graph. From the graph, we observed two minimum values of return loss i.e. $-18.9089 \mathrm{~dB}$ and $-35.5072 \mathrm{~dB}$ at resonant frequencies $10.888 \mathrm{GHz}$ and $12.316 \mathrm{GHz}$ respectively. From the results, one important observation we have made that $S_{11}$ is remaining above the below the -10dB line in the frequency range $10.531-12.4 \mathrm{GHz}$ making it very much suitable for high frequency applications. The second important 
parameter to be considered here is impedance bandwidth. It is a range of frequencies over which antenna shows good impedance matching and it is being observed from the results that these frequency ranges are $10.531-12.4 \mathrm{GHz}$ with corresponding impedance bandwidth of $1.869 \mathrm{GHz}$ respectively. The third important parameter to be observed here is VSWR i.e. voltage standing wave ratio. It shows the ratio of impedance matching between antenna and port. The simulation results for VSWR for proposed antenna design is shown in figure 3(b). Here also, we have compared the results with desired value of VSWR. It is being observed from the graph that VSWR is 1.9782 at first resonant frequency of $10.888 \mathrm{GHz}$ and is very much decreased i.e. 0.2914 at second resonant frequency of $12.316 \mathrm{GHz}$. Both the values are in acceptable range but again we observed that as we are moving towards higher frequencies, our results are getting improved continuously for all the three parameters considered hare for performance measurements.

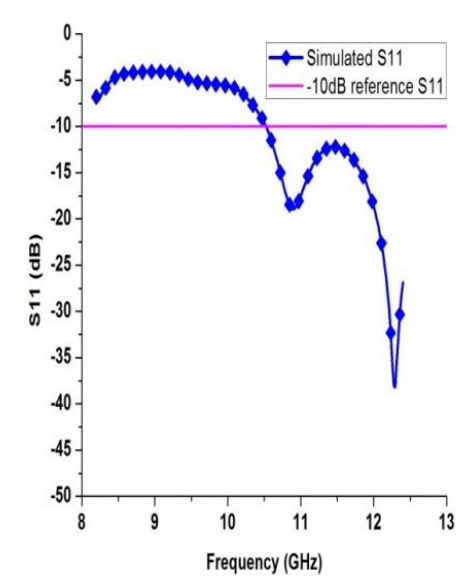

(a)

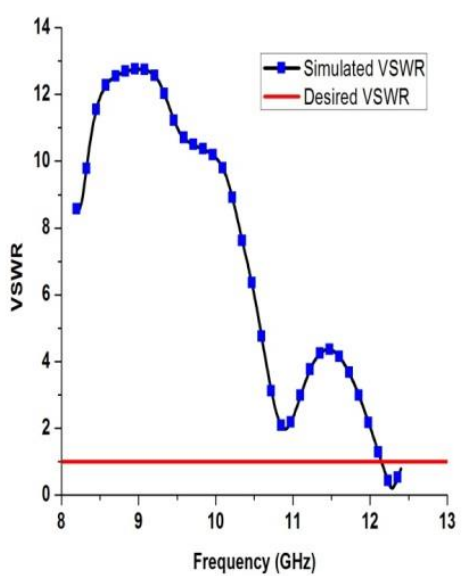

(b)

Figure 3 Represents simulation results with FR4 (a) Return loss w.r.t Frequency (b) VSWR w.r.t frequency

\section{Ga doped Ba-Sr Hexagonal ferrite as substrate}

We have prepared the Ga doped Ba-Sr hexagonal ferrite using standard ceramic method[28][30]. In this method, firstly raw material is taken and converted into different compositions. After that, heat treatments are given and lastly sample is furnished according to required application. There are certain steps which need with the raw material to be followed like weighing, mixing and grinding, drying and presintering at particular temperature. That material is again crushed in powder form and binded with PVA. Then palletization is done according to shape required [31]. In the last, the synthesized material is characterized with different techniques available for structural, electrical and magnetic properties to check the suitability of material for X-band. Microwave absorption measurement is done by calculating complex permeability, dielectric and magnetic losses. These dielectric and magnetic characterization are found using Vector Network Analyzer (VNA) method. VNA provides various scattering parameters in the frequency range $8.2 \mathrm{GHz}-$ $12.4 \mathrm{GHz}$. These parameters have a correlation with permittivity and permeability values of sample.

The complex permittivity is given as, $\varepsilon_{r}=\varepsilon^{\prime}-j \varepsilon^{\prime \prime}$

$\&$ the complex permeability is given as $\mu_{r}=\mu^{\prime}-\mu^{\prime \prime}$

Here, $\varepsilon$ ' and $\varepsilon$ " represents dielectric constant and dielectric loss respectively whereas $\mu$ ' and $\mu$ ' represents permeability and magnetic loss respectively. The loss tangent decreases with increase in frequency [28] and is given as

$\tan \delta_{\varepsilon}=\varepsilon^{\prime \prime} / \varepsilon^{\prime}$

$\tan \delta_{\mu}=\mu^{\prime \prime} / \mu^{\prime}$

Variations of these parameters are shown in figure 4 below. It is being observed from the results that $\tan \delta_{\mu}$ contributes more for microwave absorption as compared to $\tan \delta_{\varepsilon}$. Based on these results, we found that doped Ba-Sr hexagonal ferrite is suitable for our research and used it as a dielectric in antenna design to enhance the bandwidth. 

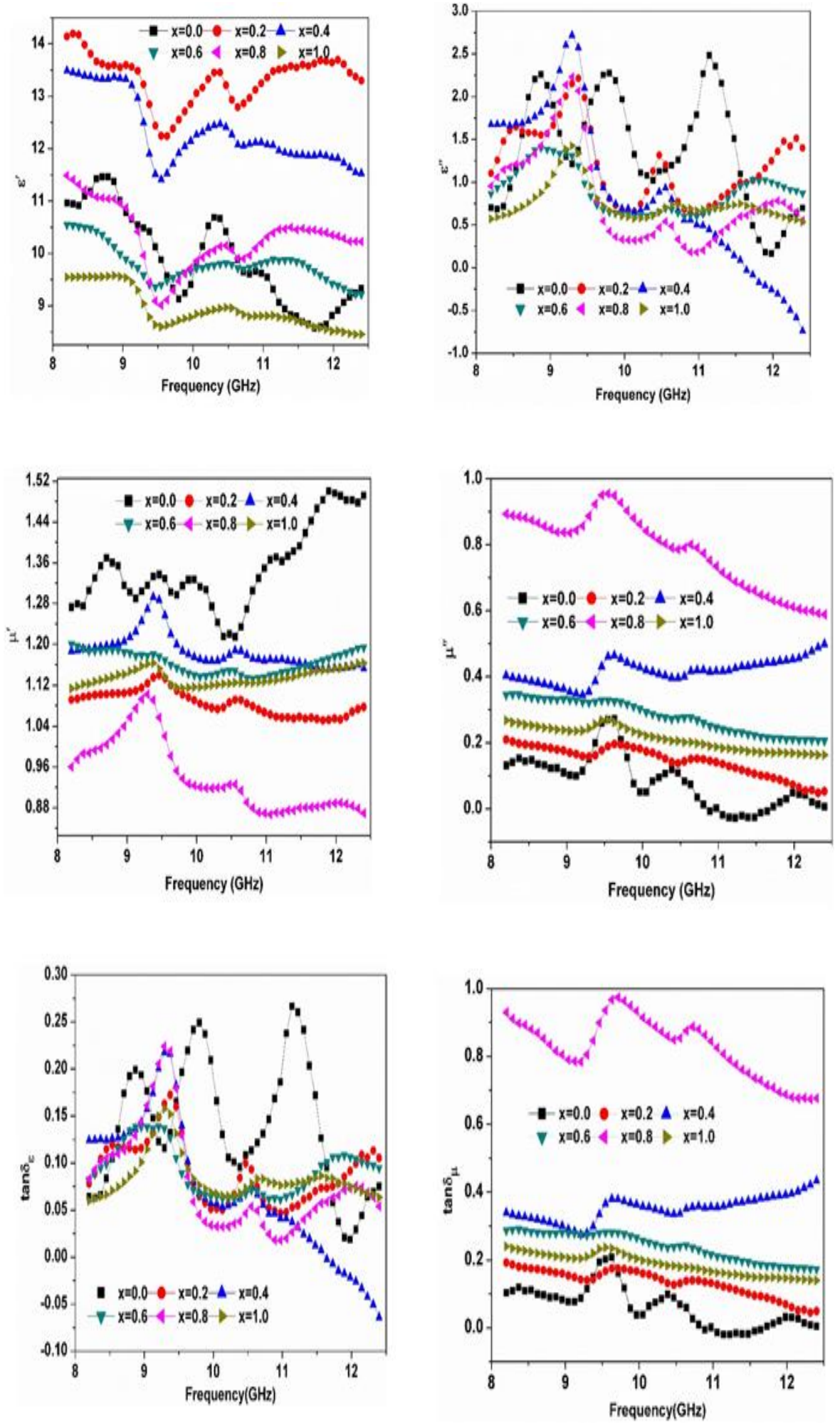

Fig 4 Variation of permittivity, permeability and loss tangents w.r.t frequency for M-Type $\mathrm{Ba}_{0.5} \mathrm{Sr}_{0.5} \mathrm{Co}_{x} \mathrm{Ga}_{x} \mathrm{Fe}_{12}-2 \mathrm{O}_{1} \mathrm{O}_{\text {hexagonal ferrite with varying }}$ doping concentration $(0 \leq \mathrm{x} \leq 1$ with steps of 0.2$)$

Various results of simulation using Ga substituted Ba-Sr hexagonal ferrite as substrate is shown below in graphs and table3. 
Table 3 Simulated results with Ga doped Ba-Sr hexagonal ferrite

\begin{tabular}{|cccc|}
\hline $\begin{array}{c}\text { Resonant } \\
\begin{array}{c}\text { Frequency } \\
(\mathrm{GHz})\end{array}\end{array}$ & $\begin{array}{l}\text { Return } \\
\text { Loss } \\
(\mathrm{dB})\end{array}$ & VSWR & Bandwidth \\
\hline 8.2 & \begin{tabular}{c} 
(12.4-8.2) $\mathrm{GHz}=4.2 \mathrm{GHz}$ \\
\hline
\end{tabular} \\
\hline
\end{tabular}

The simulated antenna using ferrite substrate is giving the operating frequency range from $8.2 \mathrm{GHz}$ to $12.4 \mathrm{GHz}$ as for the whole frequency range, the return loss is less than $-10 \mathrm{~dB}$ as shown in figure $4(\mathrm{a})$. The maximum value of return loss is 15.3319 at resonant frequency $8.2 \mathrm{GHz}$. The impedance bandwidth also got very much improved i.e. $4.2 \mathrm{GHz}$. Further, the VSWR is varying from 1 to 2 for whole frequency range of $8.2 \mathrm{GHz}$ to $12.4 \mathrm{GHz}$ with optimum value of $1.413 \mathrm{at} 8.2 \mathrm{GHz}$ as shown in figure 4(b). In both the graphs, the simulated results are compared with standard or reference value of return loss and VSWR.

\section{Comparison of simulated antenna using FR4 Epoxy substrate material and Gallium doped Ba-Sr hexagonal ferrite substrate material}

We have simulated the designed antenna with both the substrates and shown the comparison below in tabular form as well as graphically in table 4 and figure $5,6 \& 7$ respectively. It is clear from figure 5 that with fr 4 epoxy substrate, our operating frequency range is in the mid of X-band i.e. from $10.531 \mathrm{GHz}$ to $12.4 \mathrm{GHz}$ and above $-10 \mathrm{~dB}$ return loss line in the frequency range below $10.531 \mathrm{GHz}$. So, the impedance bandwidth with Fr4 epoxy substrate is $1.869 \mathrm{GHz}$. Whereas, using ferrite material as substrate, our antenna design becomes very much suitable for whole X-band range i.e. $8.2 \mathrm{GHz}$ to $12.4 \mathrm{GHz}$ as for whole range of frequency, the return loss is below $-10 \mathrm{~dB}$ i.e. minimum acceptable value of S11. That means, with ferrite material as substrate our impedance bandwidth got very much wide of $4.2 \mathrm{GHz}$. The next comparison made is of maximum value of return loss, which is large with FR4 epoxy as a substrate i.e. -35.5072 at resonant frequency of $12.316 \mathrm{GHz}$ while with ferrite material, maximum return loss we have got is -15.3319 at resonant frequency $8.2 \mathrm{GHz}$ i.e. at the starting of $\mathrm{X}$-band range as shown in figure 5. The third comparison we have made is of VSWR shown in figure 7. The VSWR obtained with both the substrates are in acceptable range but it is found to be better with FR4 epoxy substrate. With FR4 substrate, we have observed that VSWR was initially increasing from frequency $8 \mathrm{GHz}$ to $9 \mathrm{GHz}$ and it was decreasing continuously and found to be optimum i.e. 0.291424 at 12.316 at resonant frequency $12.316 \mathrm{GHz}$. On the other hand with ferrite as substrate, the VSWR was varying within 1 to 2 over the whole range of X-band and found to be optimum i.e. 1.413 at $12.316 \mathrm{GHz}$. The last comparison we have done was with the gain of antenna. From the $3 \mathrm{~d}$ plot of gain in figure 5, we observed that it is low gain antenna with both the substrates but comparatively gain is high i.e. 2.8587 with FR4 epoxy substrate.

Table 4 Comparison of simulated results with FR4 and Gallium doped ferrite substrate 


\begin{tabular}{|c|c|c|c|c|}
\hline \multicolumn{5}{|c|}{ Results with FR4 epoxy substrate } \\
\hline Resonant Frequency $(\mathrm{GHz})$ & Return Loss & VSWR & Bandwidth & $\begin{array}{l}\text { Gain } \\
\text { (dB) }\end{array}$ \\
\hline 10.888 & -18.9 & 1.978 & \multirow{2}{*}{$(12.4-10.531) \mathrm{GHz}=1.869 \mathrm{GHz}$} & \multirow{2}{*}{2.86} \\
\hline 12.316 & -35.5 & 0.291 & & \\
\hline \multicolumn{5}{|c|}{ Results with Gallium substituted $\mathrm{Ba}-\mathrm{Sr}$ hexagonal ferrite substrate } \\
\hline Resonant Frequency $(\mathrm{GHz})$ & Return Loss & VSWR & Bandwidth & $\begin{array}{l}\text { Gain } \\
(\mathrm{dB})\end{array}$ \\
\hline 8.2 & -15.33 & 1.41 & $(12.4-8.2) \mathrm{GHz}=4.2 \mathrm{GHz}$ & -6.4 \\
\hline
\end{tabular}

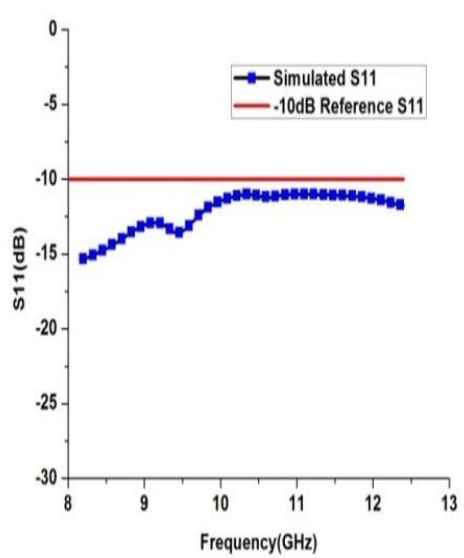

(a)

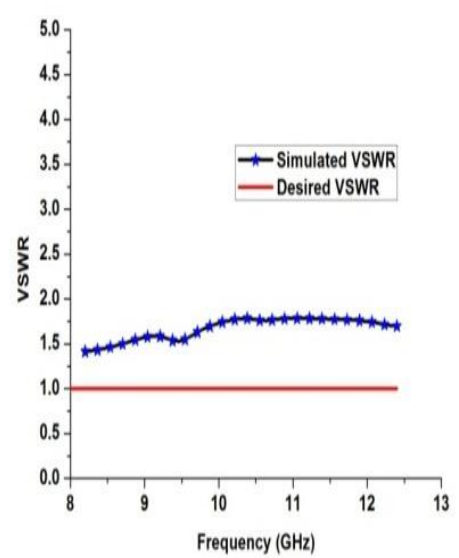

(b)

Figure 5 Represents simulation results with Gallium doped Ba-Sr hexagonal ferrite substrate (a) Return loss w.r.t Frequency (b) VSWR w.r.t frequency
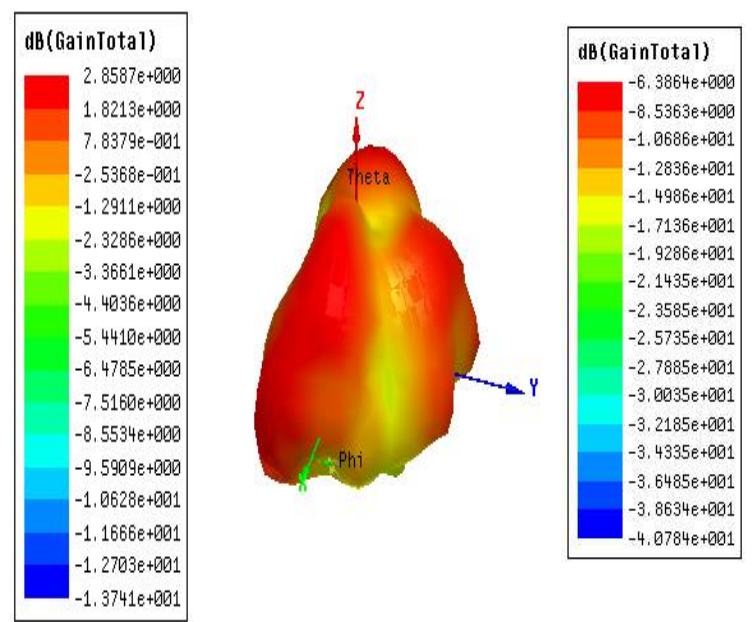

(a)

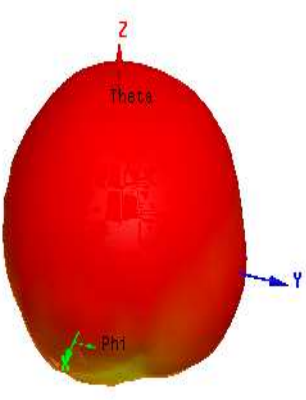

(b)

Figure 6 Gain of simulated antenna (a) using FR4 epoxy substrate (b) using Gallium doped Ba-Sr hexagonal Ferrite 


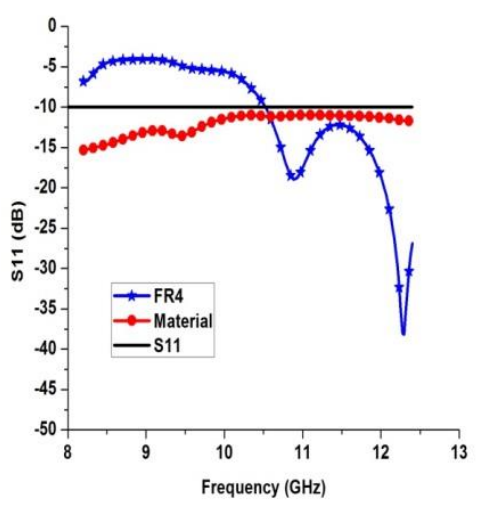

(a)

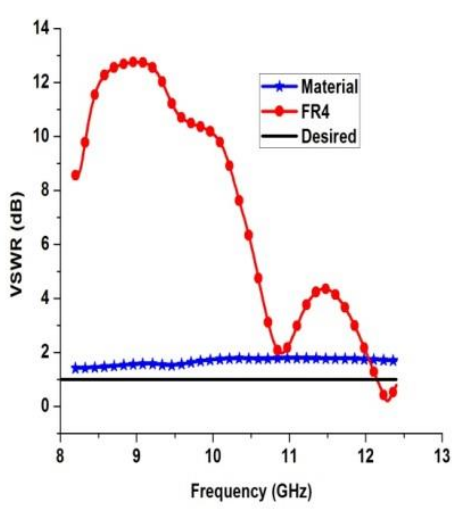

(b)

Figure 7 Comparison of simulated results using FR4 epoxy substrate and Gallium doped Ba-Sr hexagonal Ferrite (a) return loss parameter (b) VSWR

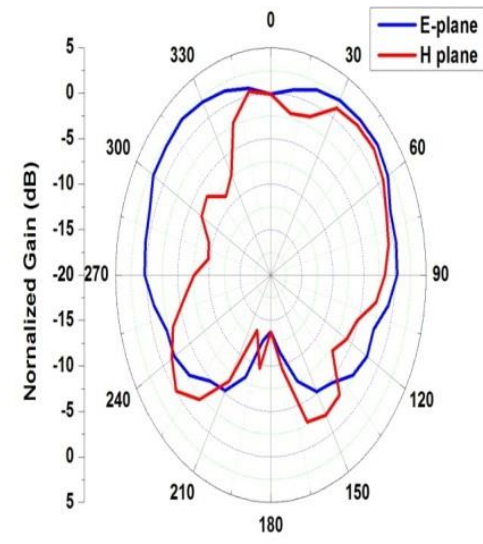

(a)

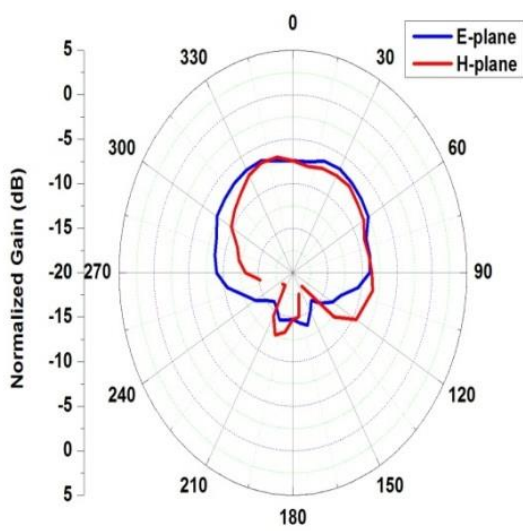

( b )

Figure 8: E-Plane/H-Plane simulated radiation pattern at 10GHz center frequency (a) using FR4 epoxy substrate (b) using Ga doped ferrite material

From the results of E-H plane of radiation pattern shown in figure 8, it was observed that using both the substrates, the radiation pattern is quite directional having wide lobe in front and minor lobes in back for both $\mathrm{E}$ and $\mathrm{H}$-plane but the gain is very low using ferrite substrate.

\section{Fabrication and Measurements}

The designed antenna is fabricated using FR4 epoxy substrate and measurement for microwave absorption is done using VNA i.e. Vector Network Analyzer method as shown in figure 9 (a \& b). The VNA method provides various scattering parameters in the frequency range $8.2 \mathrm{GHz}$ to $12.4 \mathrm{GHz}$. The measured results for return loss and VSWR are compared with simulated results in figure 10. It is clear from figure 10 (a) that the fabricated antenna has three operating frequency ranges i.e. $9.54 \mathrm{GHz}-10.145 \mathrm{GHz}, 10.585 \mathrm{GHz}-11.7125 \mathrm{GHz}$ and $11.96 \mathrm{GHz}-12.5375 \mathrm{GHz}$ showing bandwidth of $605 \mathrm{MHz}, 1.1275 \mathrm{GHz} \& 577.5 \mathrm{MHz}$ respectively. There are three resonant frequencies with -48.254578 optimum value of return loss at $11.025 \mathrm{GHz}$. Whereas in simulated results, two resonant frequencies were there and minimum return loss was -35.5072 at $12.316 \mathrm{GHz}$. From the results of VSWR as shown in figure 10 (b), we have observed that impedance matching is very much poor below $9.54 \mathrm{GHz}$ and above $12.4 \mathrm{GHz}$, but within this range, it is quite acceptable. 


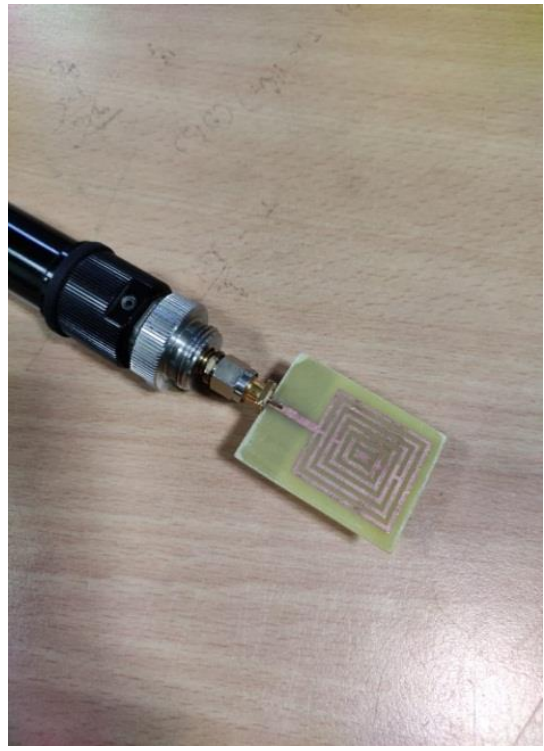

(a)

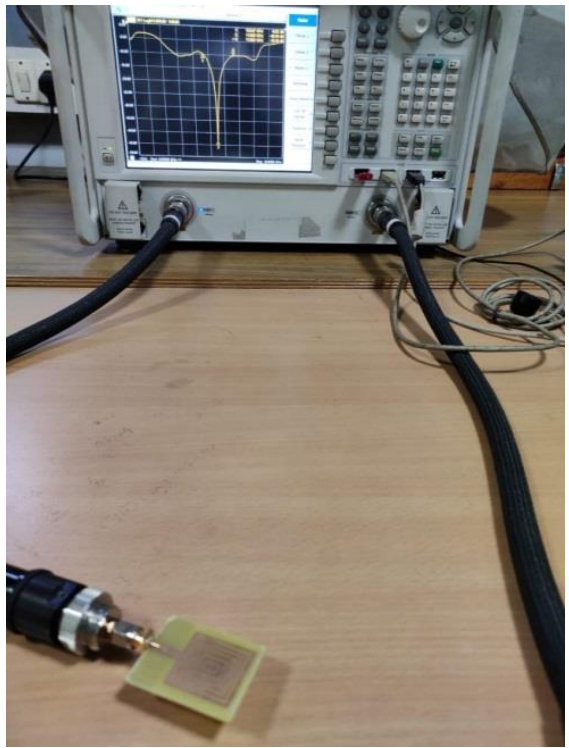

(b)

Figure $9(a, b)$ : Fabricated antenna measurement using Vector Network Analyzer

The optimum value of VSWR is 1.00698 at $11.025 \mathrm{GHz}$. While, it was being observed from the simulated results that VSWR was remaining very high below $12 \mathrm{GHz}$ and was acceptable in the frequency range $12 \mathrm{GHz}-12.4 \mathrm{GHz}$. The optimum value of VSWR is 0.2914 at $12.316 \mathrm{GHz}$. All the results of simulation as well as measured is compared in tabular form are shown in table 5 below.

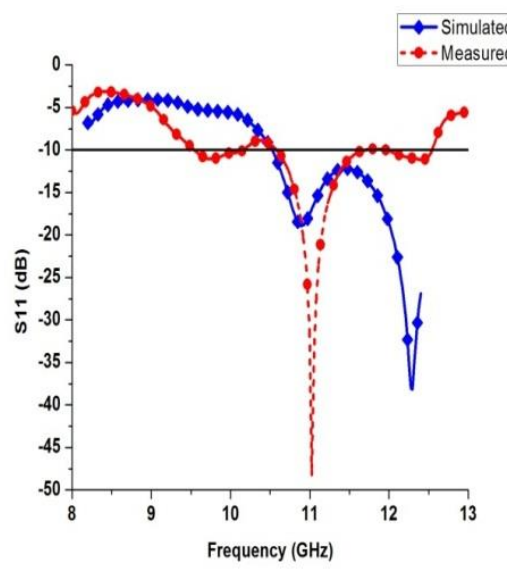

(a)

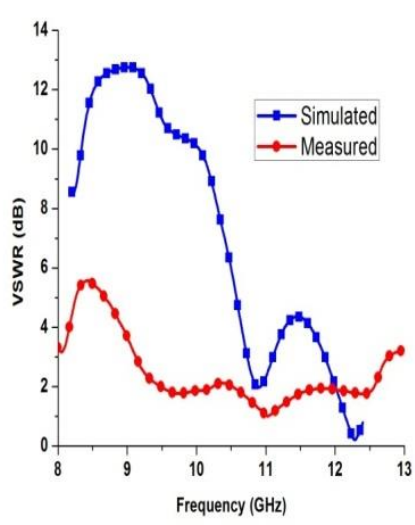

(b)

Figure 10: Comparison of Measured and Simulated results using FR4 epoxy substrate (a) Return loss parameter (b) VSWR

Table 5: Comparison of Simulated results with Measured results using FR4 epoxy substrate:

\begin{tabular}{|c|c|c|c|}
\hline \multicolumn{4}{|c|}{ Simulated Results } \\
\hline $\begin{array}{l}\text { Resonant } \\
\text { Frequency } \\
\text { (GHz) }\end{array}$ & Return Loss & VSWR & Bandwidth \\
\hline 10.888 & -18.9089 & 1.97821 & \multirow{2}{*}{$=(12.4-10.531) \mathrm{GHz}=1.869 \mathrm{GHz}$} \\
\hline 12.316 & -35.5072 & 0.29142 & \\
\hline \multicolumn{4}{|c|}{ Measured Results } \\
\hline $\begin{array}{l}\text { Resonant } \\
\text { Frequency } \\
\text { (GHz) }\end{array}$ & Return Loss & VSWR & Bandwidth \\
\hline
\end{tabular}




\begin{tabular}{|l|l|l|l|}
\hline 9.7325 & -11.06 & 1.77626 & $=(10.145-9.54) \mathrm{GHz}=605 \mathrm{MHz}$ \\
\hline 11.025 & -48.25458 & 1.00698 & $\begin{array}{l}=(11.7125- \\
10.585) \mathrm{GHz}=1.1275 \mathrm{GHz}\end{array}$ \\
\hline 12.4 & -11.1484 & 1.75881 & $=(12.5375-11.96) \mathrm{GHz}=577.5 \mathrm{MHz}$ \\
\hline
\end{tabular}

Further, for measuring the radiation pattern of fabricated antenna, it was being placed in anechoic chamber as shown in figure 11. An anechoic chamber provides an RF proof environment where both the antenna and measurement devices are isolated from outside interference and stray field and useful for studying the 2D and 3D radiation pattern of antenna. The 2D radiation pattern plot of fabricated antenna for both E-plane (phi=90 deg) and $\mathrm{H}$-plane (phi= $0 \mathrm{deg}$ ) is given in figure 12 below. Both simulated as well as measured radiation pattern is compared in that plot.

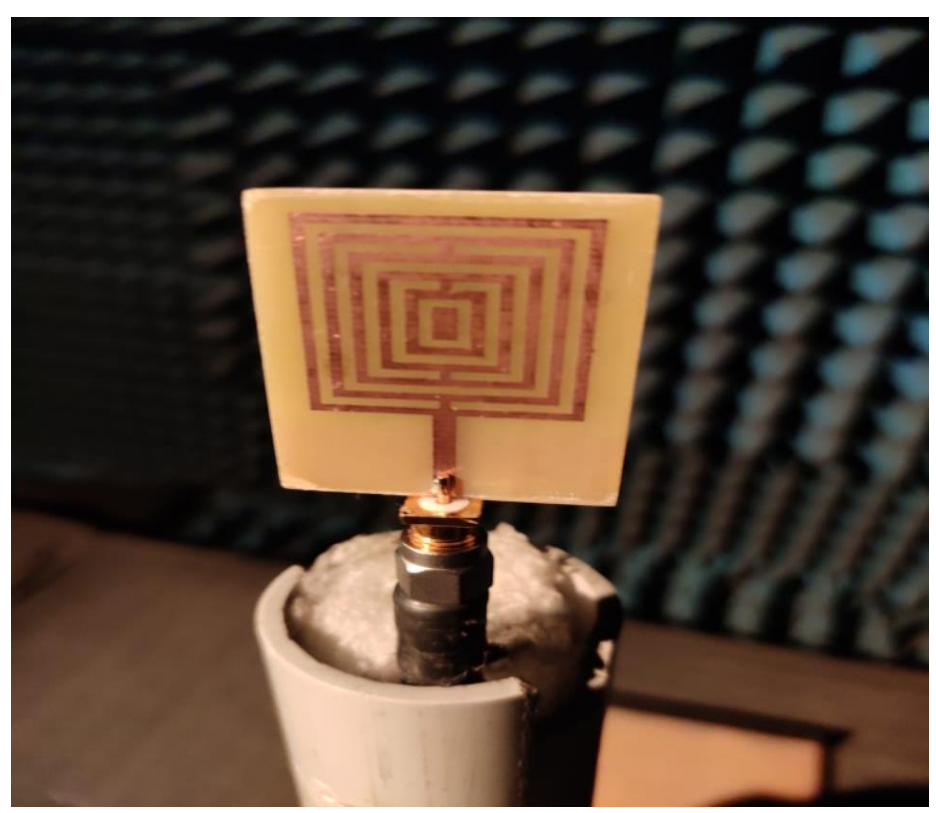

Fig: 11 Measurement setup of the fabricated antenna in Anechoic Chamber
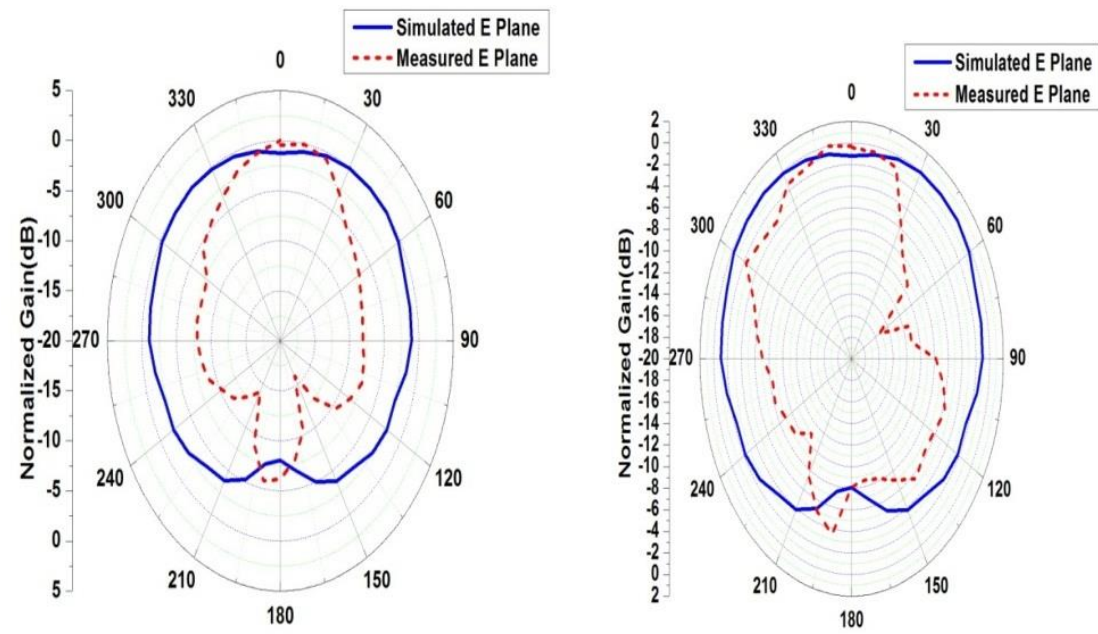

(a)

(b) 


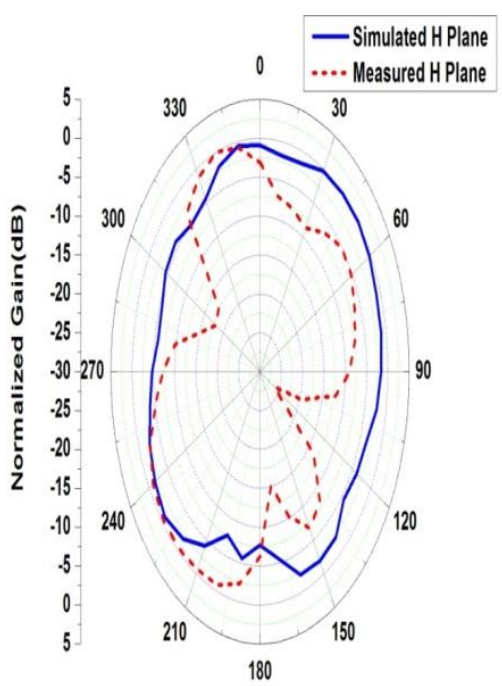

(c)

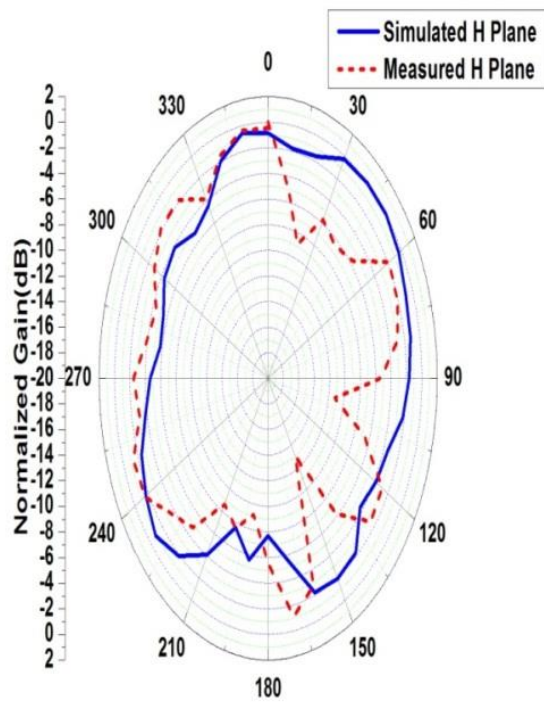

(d)

Figure 12: Comparison of simulated as well as measured radiation pattern of proposed antenna using FR4 substrate (a) simulated E-plane at 10GHZ and measured E-Plane at $10.54 \mathrm{GHz}$ (b) simulated E-plane at $10 \mathrm{GHZ}$ and measured E-Plane at $11.98 \mathrm{GHz}$ (c) simulated $\mathrm{H}$-plane at $10 \mathrm{GHZ}$ and measured H-Plane at $10.54 \mathrm{GHz}$ (d) simulated H-plane at $10 \mathrm{GHZ}$ and measured H-Plane at $11.98 \mathrm{GHz}$.

\section{Conclusions}

A novel microstrip patch antenna is designed using Gallium doped $\mathrm{Ba}-\mathrm{Sr}$ hexagonal ferrite substrate for portable applications in X-band. The results are compared with the same antenna design using FR4 epoxy substrate. We have observed a wide Bandwidth of $4.2 \mathrm{GHz}(8.2 \mathrm{GHz}-12.4 \mathrm{GHz})$ from this novel antenna design using ferrite substrate as return loss is lying below $-10 \mathrm{~dB}$ for whole $\mathrm{X}$-band range. That makes it very much suitable for all $\mathrm{X}$-band applications of RADAR, Satellite, Wireless communication, Weather forecasting etc. Although, the other parameters obtained like return loss, VSWR and gain are found to be optimum using FR4 substrate but it is in acceptable range with Gallium doped BaSr hexagonal ferrite substrate. The proposed antenna design with FR4 substrate is verified experimentally and measured results are found to be in close proximity to simulated results.

Acknowledgments We would like to thanks Assistant Professor, Dr. Akshay Kumar, Department of Nanotechnology, SGGSW University, Fatehgarh Sahib, Punjab for providing the laboratory facilities. Further we would like to acknowledge the cooperation of staff members of nanotechnology department of this aforementioned University. 


\section{$\underline{\text { Declarations }}$}

On behalf of all authors it is hereby to confirm that

1. There was not funding available from any agencies to impart this research work.

2. There is no any Conflicts of interest/Competing interests (include appropriate disclosures) by any authors or external sources

3. Authors are ready to provide related data for this research article as and when desired.

4. There is no any code availability for this work

5. All authors included in the research article have contributed directly or indirectly for this work 


\section{References}

1. Row JS, Liou YY (2006) Broadband short-circuited triangular patch antenna. IEEE Trans Antennas Propag 54:2137-2141 . https://doi.org/10.1109/TAP.2006.875916

2. Vettikalladi H, Lafond O, Himdi M (2009) High-efficient and high-gain superstrate antenna for $60-\mathrm{GHz}$ indoor communication. IEEE Antennas Wirel Propag Lett 8:1422-1425 . https://doi.org/10.1109/LAWP.2010.2040570

3. Bait-Suwailam MM, Siddiqui OF, Ramahi OM (2010) Mutual coupling reduction between microstrip patch antennas using slotted-complementary split-ring resonators. IEEE Antennas Wirel Propag Lett 9:876-878 . https://doi.org/10.1109/LAWP.2010.2074175

4. Peng L, Ruan C-L, Wu X-H (2010) Design and Operation of Dual / Triple-Band Patch Antennas. IEEE Antennas Wirel Propag Lett 9:1069-1072

5. Zhang J, Wang J, Chen M, Zhang Z (2012) RCS reduction of patch array antenna by electromagnetic band-gap structure. IEEE Antennas Wirel Propag Lett 11:1048-1051. https://doi.org/10.1109/LAWP.2012.2215832

6. Pucci E, Rajo-Iglesias E, Ng Mou Kehn M, Quevedo-Teruel O (2012) Enhancing the efficiency of compact patch antennas composed of split-ring resonators by using lumped capacitors. IEEE Antennas Wirel Propag Lett 11:1362-1365 . https://doi.org/10.1109/LAWP.2012.2227662

7. Jothi Chitra R, Nagarajan V (2013) Double L-slot microstrip patch antenna array for WiMAX and WLAN applications. Comput Electr Eng 39:1026-1041 https://doi.org/10.1016/j.compeleceng.2012.11.024

8. Motin MA, Hasan MI, Asaduz-Zaman M (2012) Design and optimization of a low cost multi band microstrip patch antenna for K-band, Ku-band and X-band applications. Proceeding 15th Int Conf Comput Inf Technol ICCIT 2012 615-620 . https://doi.org/10.1109/ICCITechn.2012.6509750

9. Vani HR, Goutham MA, Paramesha (2019) Gain enhancement of microstrip patch antenna using metamaterial superstrate. Appl Comput Electromagn Soc J 34:823-826

10. Kumar A, Kumar M (2014) Gain enhancement in a novel square microstrip patch antenna using metallic rings. Int Conf Recent Adv Innov Eng ICRAIE 2014 9-12 . https://doi.org/10.1109/ICRAIE.2014.6909168

11. Han W, Yang F, Long R, Zhou L, Yan F (2015) Bandwidth enhancement for single-feed circularly polarised microstrip antenna with epsilon-negative transmission line-based annular ring. Electron Lett 51:1475-1476 . https://doi.org/10.1049/el.2015.1258

12. Situ Rani Patre and Surya P. Singh (2013) CPW-FED FLOWER-SHAPED PATCH ANTENNA FOR BROADBAND APPLICATIONS. Microw Opt Technol Lett 55:2562-2568. https://doi.org/10.1002/mop

13. Rabbani MS, Ghafouri-Shiraz H (2016) Improvement of microstrip patch antenna gain and bandwidth at $60 \mathrm{GHz}$ and $\mathrm{X}$ bands for wireless applications. IET Microwaves, Antennas Propag 10:1167-1173 . https://doi.org/10.1049/iet-map.2015.0672

14. Deshmukh AA, Singh D, Zaveri P, Gala M, Ray KP (2016) Broadband Slot Cut Rectangular Microstrip Antenna. Procedia Comput Sci 93:53-59 . https://doi.org/10.1016/j.procs.2016.07.181

15. Gao XJ, Cai T, Zhu L (2016) Enhancement of gain and directivity for microstrip antenna using negative permeability metamaterial. AEU - Int $J$ Electron Commun 70:880-885 . https://doi.org/10.1016/j.aeue.2016.03.019

16. Feng G, Chen L, Xue X, Shi X (2017) Broadband Surface-Wave Antenna with a Novel Nonuniform Tapered Metasurface. IEEE Antennas Wirel Propag Lett 16:2902-2905. https://doi.org/10.1109/LAWP.2017.2751621

17. Hu Y, Wang Y, Liang L, He Y, Chen W, Yan Z (2018) Study on Circularly Polarized Patch Antenna with Asymmetric Chiral Metamaterial. IEEE Antennas Wirel Propag Lett 17:907-910 . https://doi.org/10.1109/LAWP.2018.2822820

18. Patel SK, Argyropoulos C, Kosta YP (2018) Pattern controlled and frequency tunable microstrip antenna loaded with multiple split ring resonators. IET Microwaves, Antennas Propag 12:390394 . https://doi.org/10.1049/iet-map.2017.0319

19. Varamini G, Keshtkar A, Naser-Moghadasi M (2018) Miniaturization of microstrip loop antenna for wireless applications based on metamaterial metasurface. AEU - Int J Electron Commun 83:32-39 . https://doi.org/10.1016/j.aeue.2017.08.024

20. Yang ZZ, Liang F, Yi Y, Zhao D, Wang BZ (2019) Metasurface-based wideband, low-profile, and high-gain antenna. IET Microwaves, Antennas Propag 13:436-441. https://doi.org/10.1049/iet-map.2018.5111

21. Gupta N, Saxena J, Bhatia KS (2019) Design of Wideband Flower-Shaped Microstrip Patch Antenna for Portable Applications. Wirel Pers Commun 109:17-30. 
https://doi.org/10.1007/s11277-019-06547-z

22. Sarmah D, Bhattacharyya N, Bhattacharyya S (2013) Study of graded composite (LDPE/TIO2) materials as substrate for microstrip patch antennas in X-band. IEEE Trans Dielectr Electr Insul 20:1845-1850 . https://doi.org/10.1109/TDEI.2013.6633716

23. Saxena NK, Singh B, Kumar N, Pourush PKS (2012) Microstrip triangular patch antenna fabricated on LiTiZn ferrite substrate and tested in the X band range. AEU - Int J Electron Commun 66:140-142 . https://doi.org/10.1016/j.aeue.2011.06.002

24. Saxena NK, Kumar N, Pourush PKS (2015) Radiation characteristics of microstrip rectangular patch antenna fabricated on LiTiMg ferrite substrate. AEU - Int J Electron Commun 69:17411744 . https://doi.org/10.1016/j.aeue.2015.08.005

25. Bhongale SR, Ingavale HR, Shinde TJ, Vasambekar PN (2018) Microwave sintered Mg-Cd ferrite substrates for microstrip patch antennas in X-band. AEU - Int J Electron Commun 96:246-251 . https://doi.org/10.1016/j.aeue.2018.09.040

26. Hasan IH, Hamidon MN, Ismail A, Ismail I, Mekki AS, Mohd Kusaimi MA, Azhari S, Osman R (2018) YIG Thick Film as Substrate Overlay for Bandwidth Enhancement of Microstrip Patch Antenna. IEEE Access 6:32601-32611 . https://doi.org/10.1109/ACCESS.2018.2842749

27. Bhongale SR (2020) Mg-Nd-Cd ferrite as substrate for X-band microstrip patch antenna. J Magn Magn Mater 499:165918 . https://doi.org/10.1016/j.jmmm.2019.165918

28. Kaur H, Marwaha A, Singh C, Narang SB, Jotania R, Jacobo S, Sombra ASB, Trukhanov S V., Trukhanov A V., Dhruv P (2019) Investigation of structural, hysteresis and electromagnetic parameters for microwave absorption application in doped $\mathrm{Ba}-\mathrm{Sr}$ hexagonal ferrites at X-band. $\mathbf{J}$ Alloys Compd 806:1220-1229 . https://doi.org/10.1016/j.jallcom.2019.07.032

29. Hansen RC, Burke M (2000) Antennas with magneto-dielectrics. Microw Opt Technol Lett 26:75-78 . https://doi.org/10.1002/1098-2760(20000720)26:2<75::AID-MOP3>3.0.CO;2-W

30. Joshi R, Singh C, Singh J, Kaur D, Narang SB, Jotania RB (2017) A study of microwave absorbing properties in Co-Gd doped M-type Ba-Sr hexaferrites prepared using ceramic method. J Mater Sci Mater Electron 28:11969-11978 . https://doi.org/10.1007/s10854-017-7006-3

31. Rani M, Bhatia KS, Singh H, Kaur H, Gupta N (2020) Synthesis of suitable material for microwave absorbing properties in X-band. SN Appl Sci 2: . https://doi.org/10.1007/s42452-020$03786-9$ 
Figures

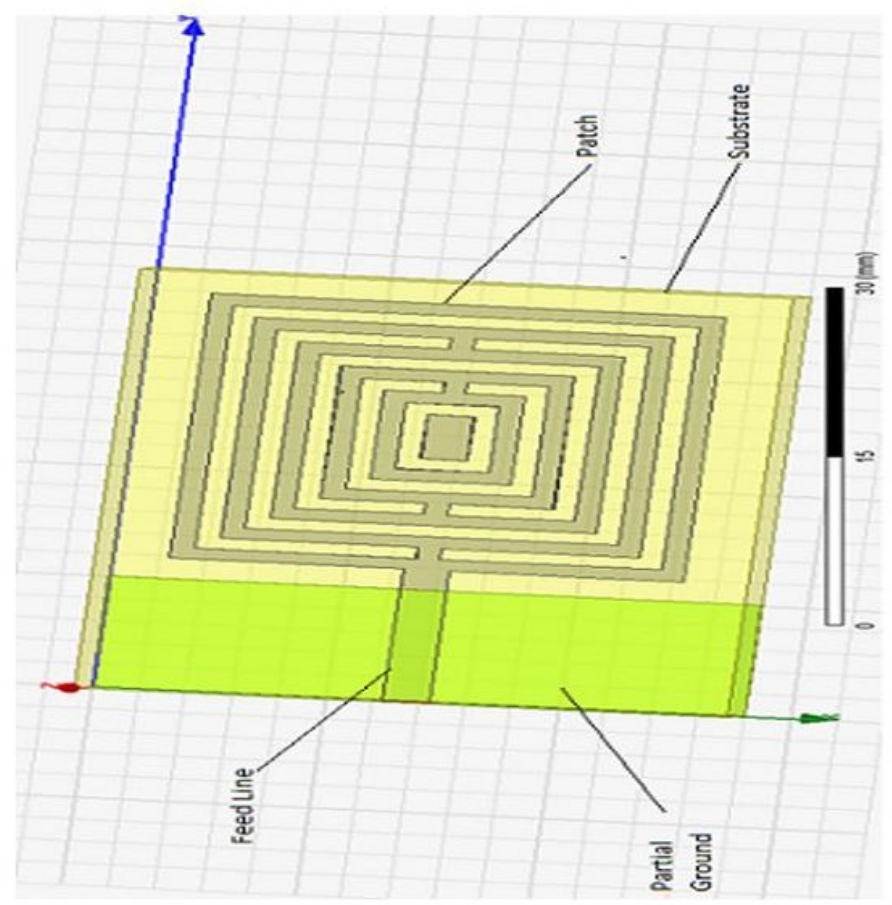

(a)

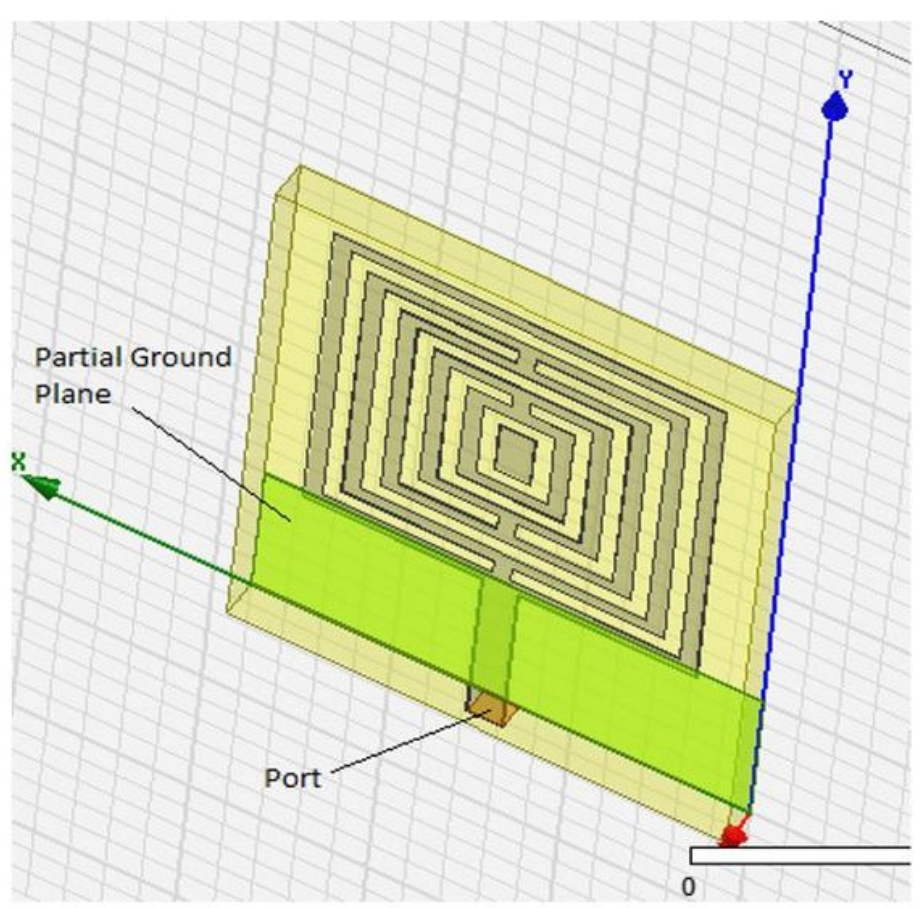

(b)

Figure 1

Software design Layout of proposed antenna (a) Top view (b) Bottom view 


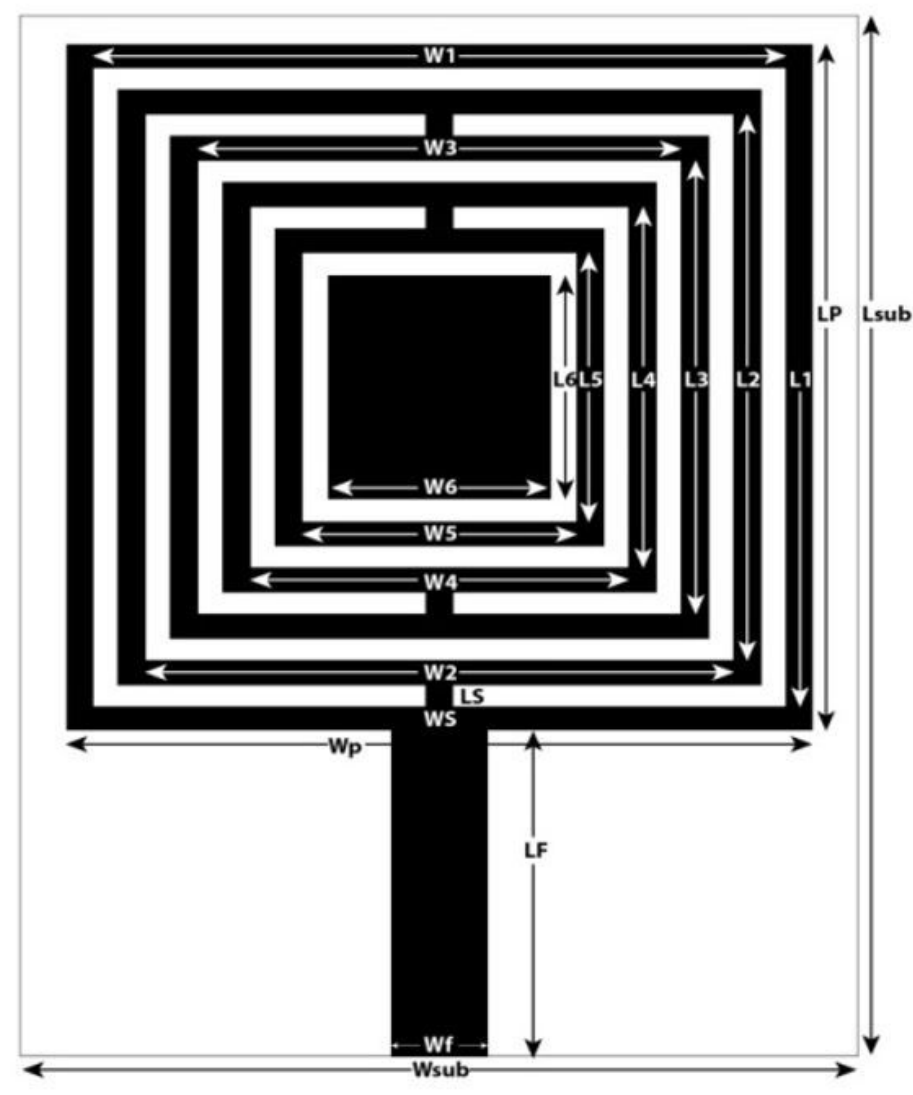

(a)

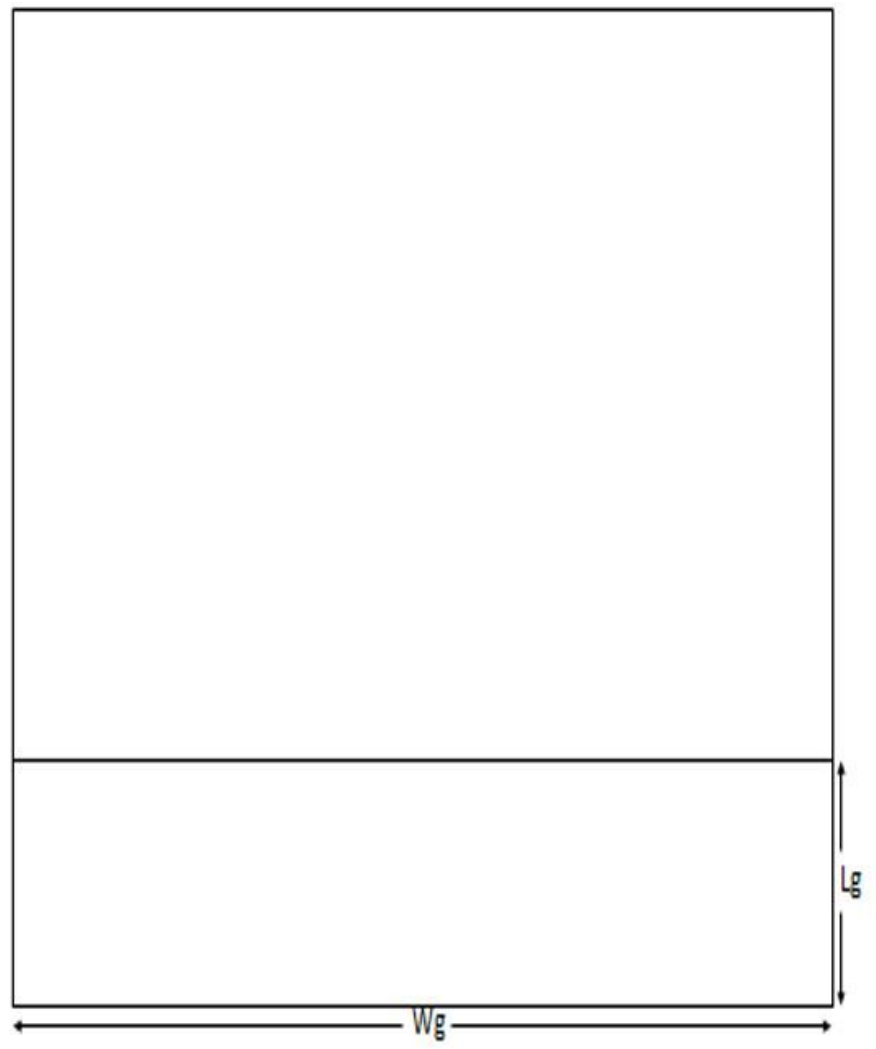

(b)

Figure 2

Structure of proposed antenna design (a) Front view (b) Back view 


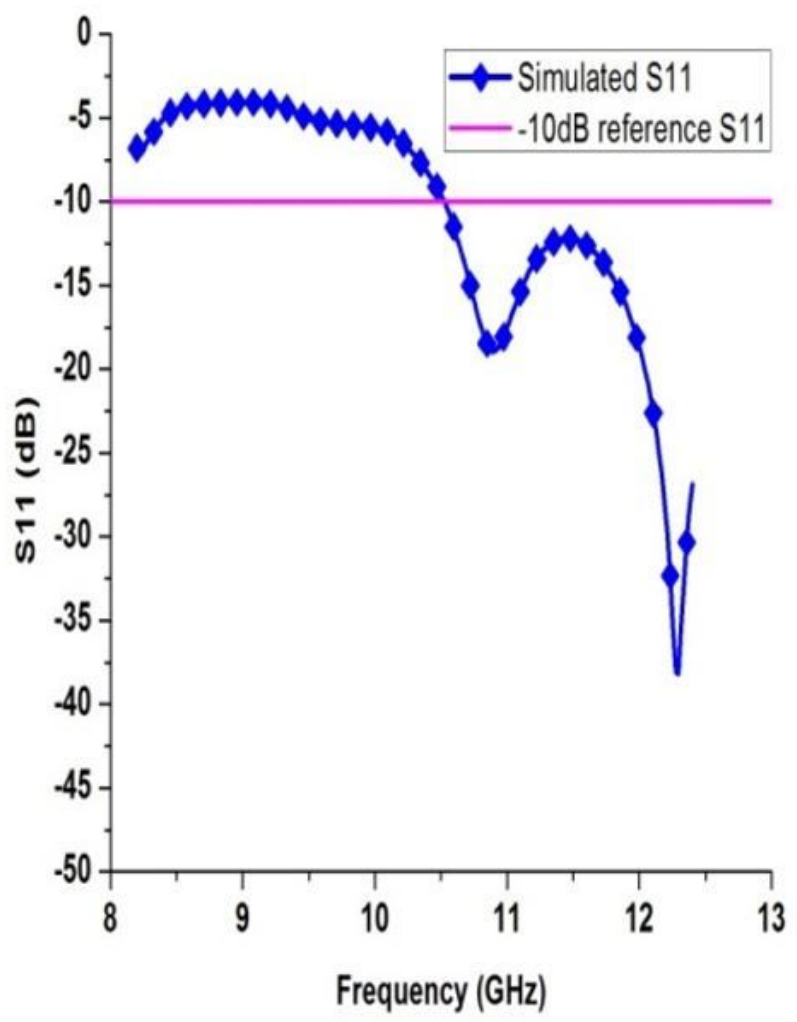

(a)

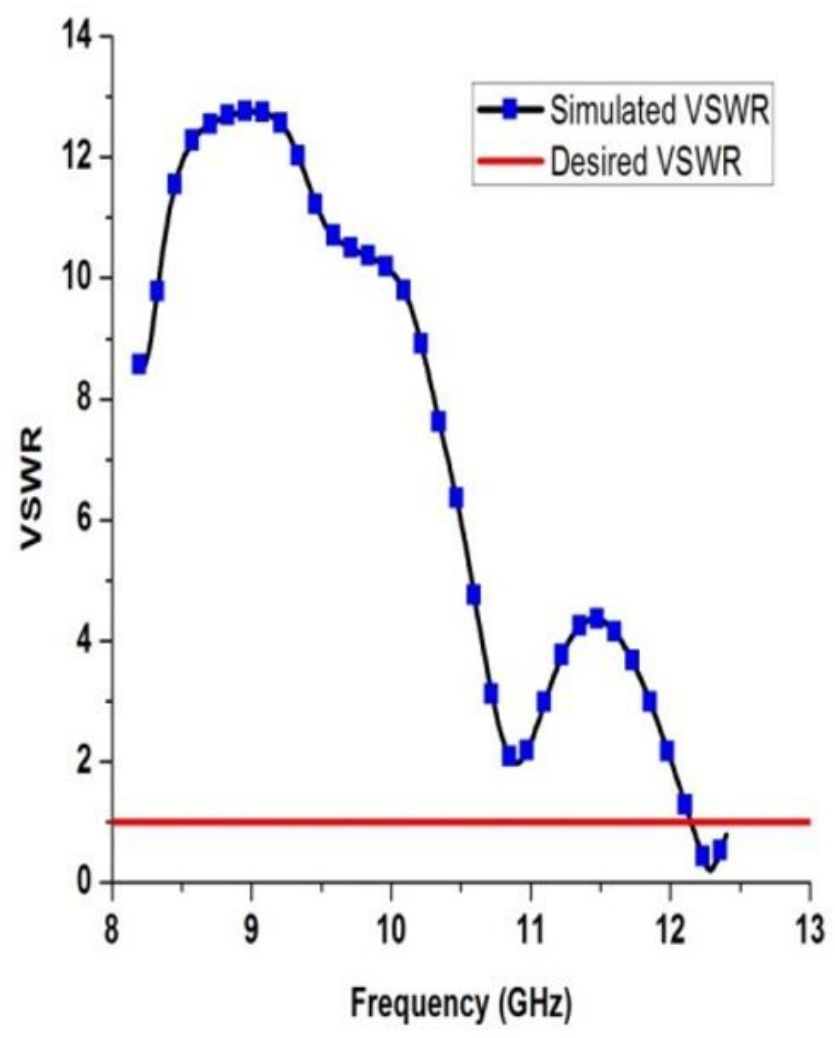

(b)

Figure 3

Represents simulation results with FR4 (a) Return loss w.r.t Frequency (b) VSWR w.r.t frequency 

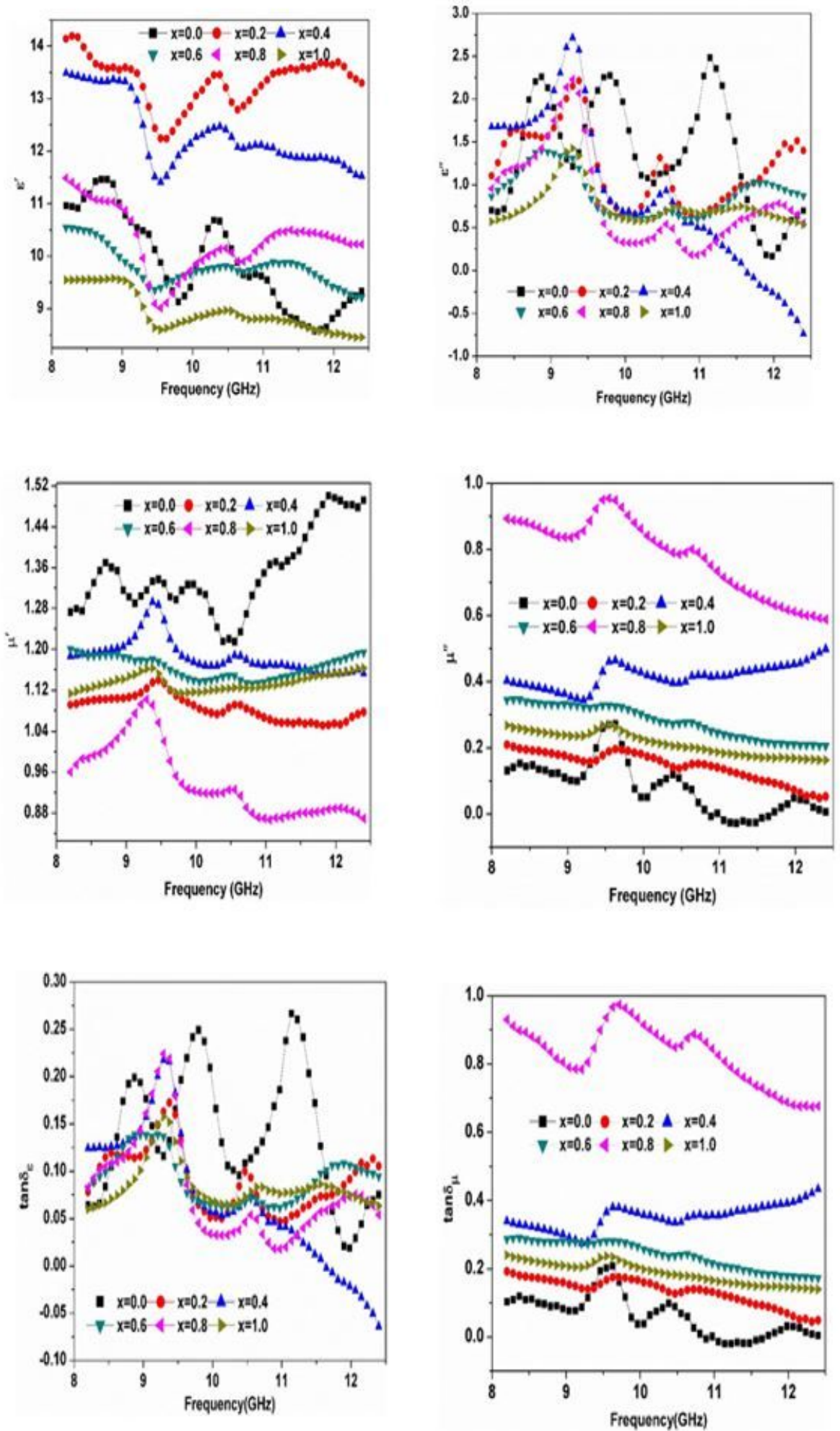

Figure 4

Variation of permittivity, permeability and loss tangents w.r.t frequency for M-Type Ba0.5Sr0.5CoxGaxFe12-019 2x019hexagonal ferrite with varying doping concentration $(0<\mathrm{x}<1$ with steps of 0.2$)$ 


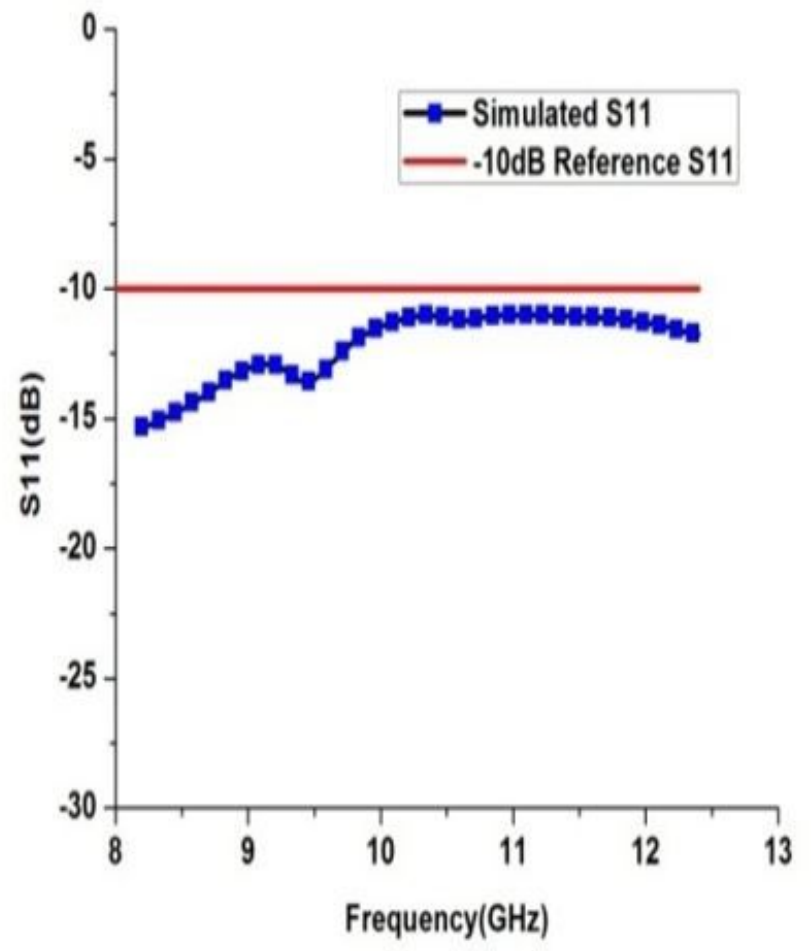

(a)

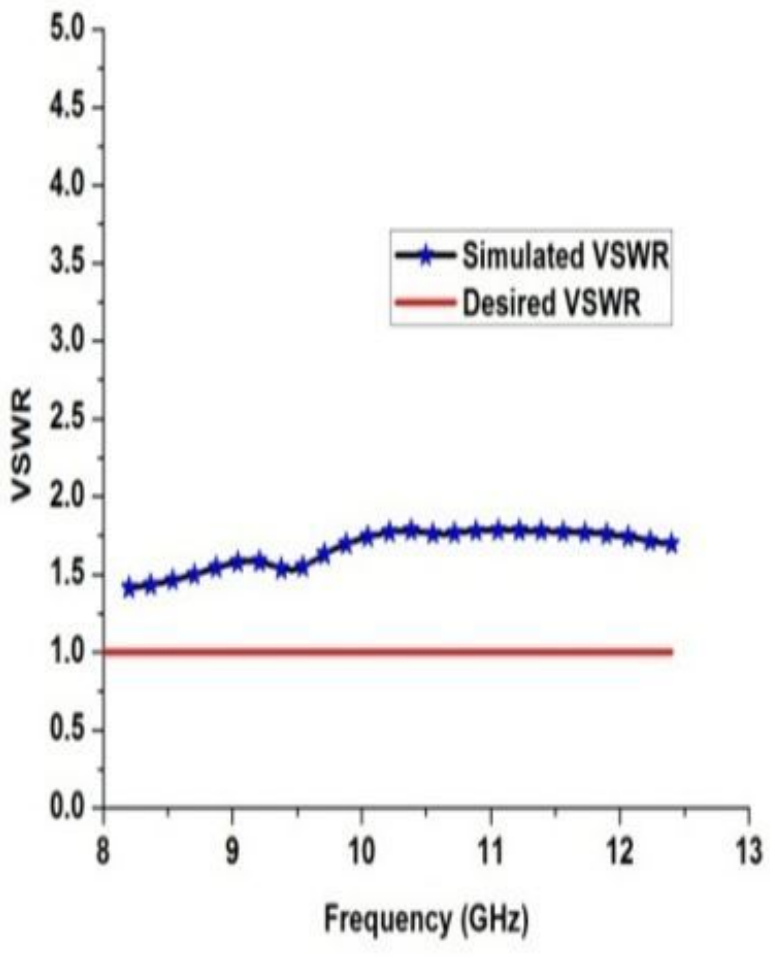

(b)

\section{Figure 5}

Represents simulation results with Gallium doped Ba-Sr hexagonal ferrite substrate (a) Return loss w.r.t Frequency (b) VSWR w.r.t frequency 

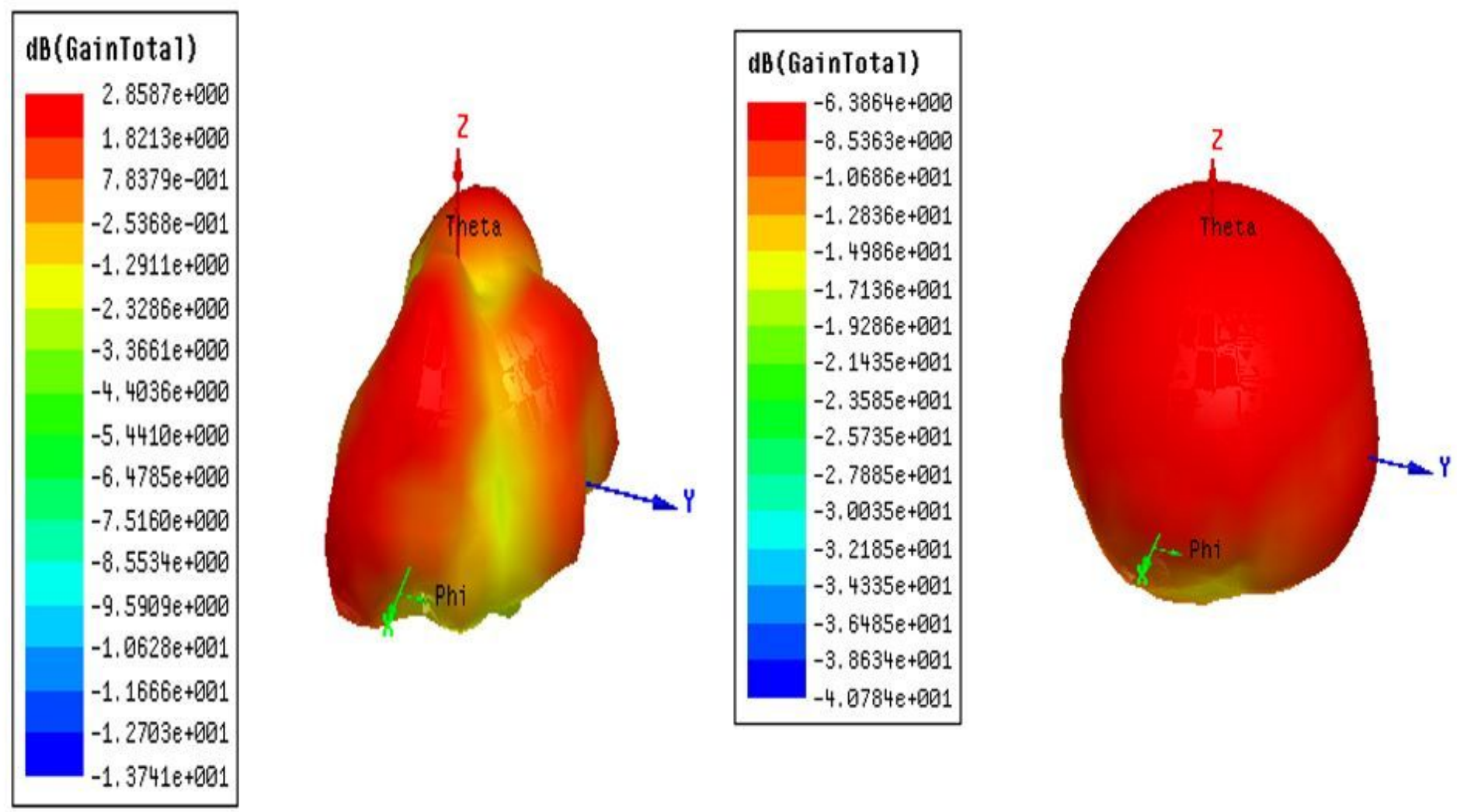

(a)

(b)

\section{Figure 6}

Gain of simulated antenna (a) using FR4 epoxy substrate (b) using Gallium doped Ba-Sr hexagonal Ferrite

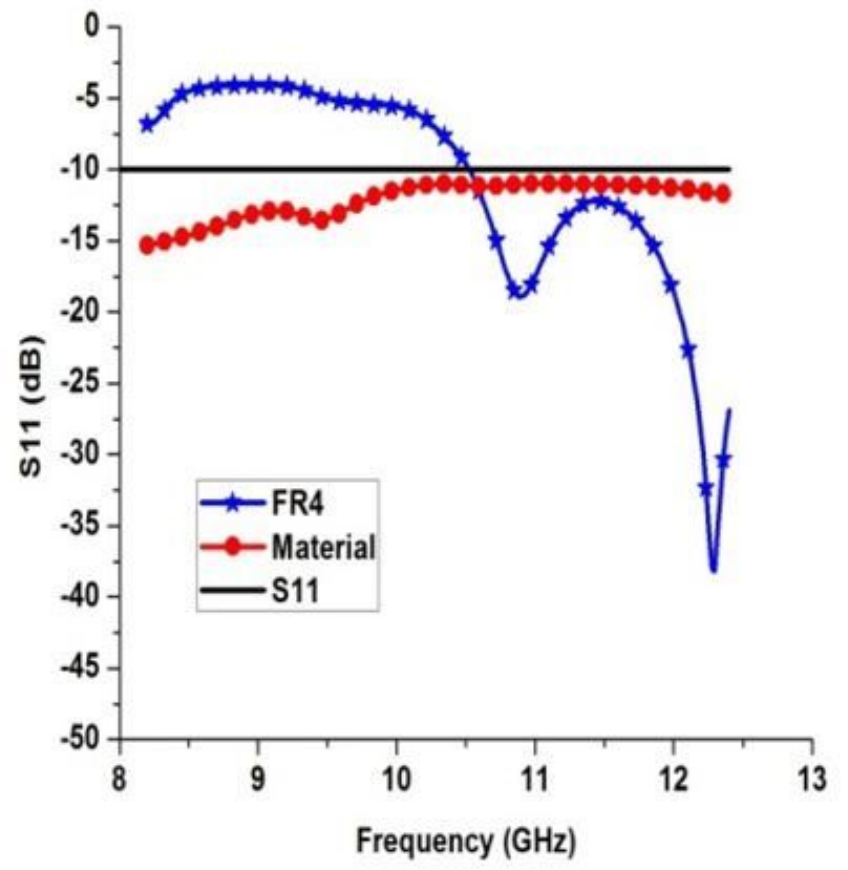

(a)

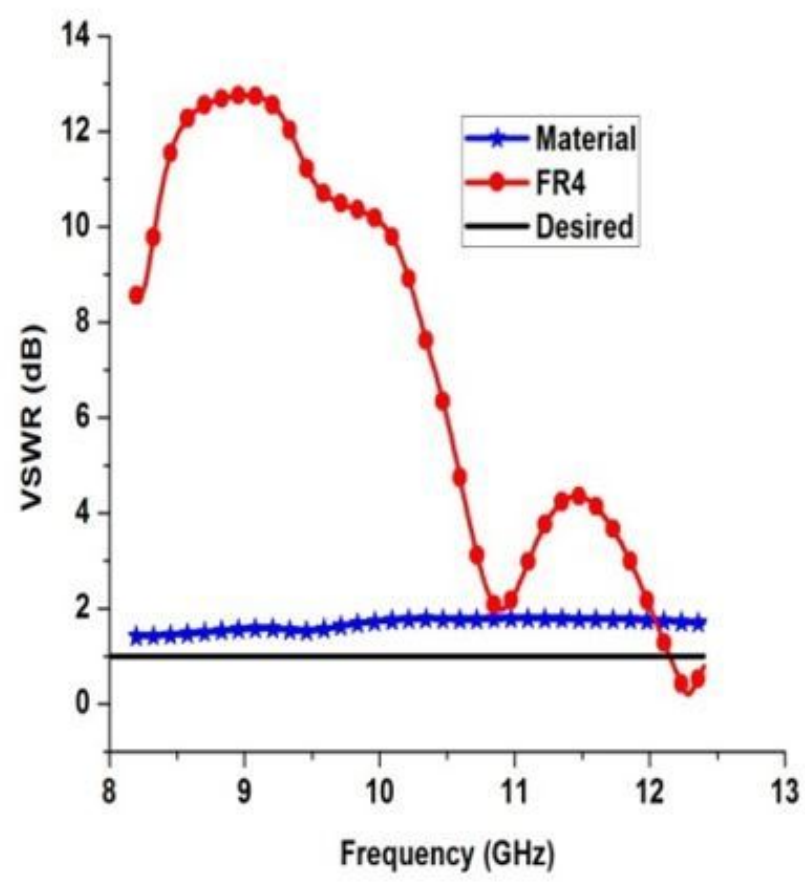

(b) 
Figure 7

Comparison of simulated results using FR4 epoxy substrate and Gallium doped Ba-Sr hexagonal Ferrite (a) return loss parameter (b) VSWR

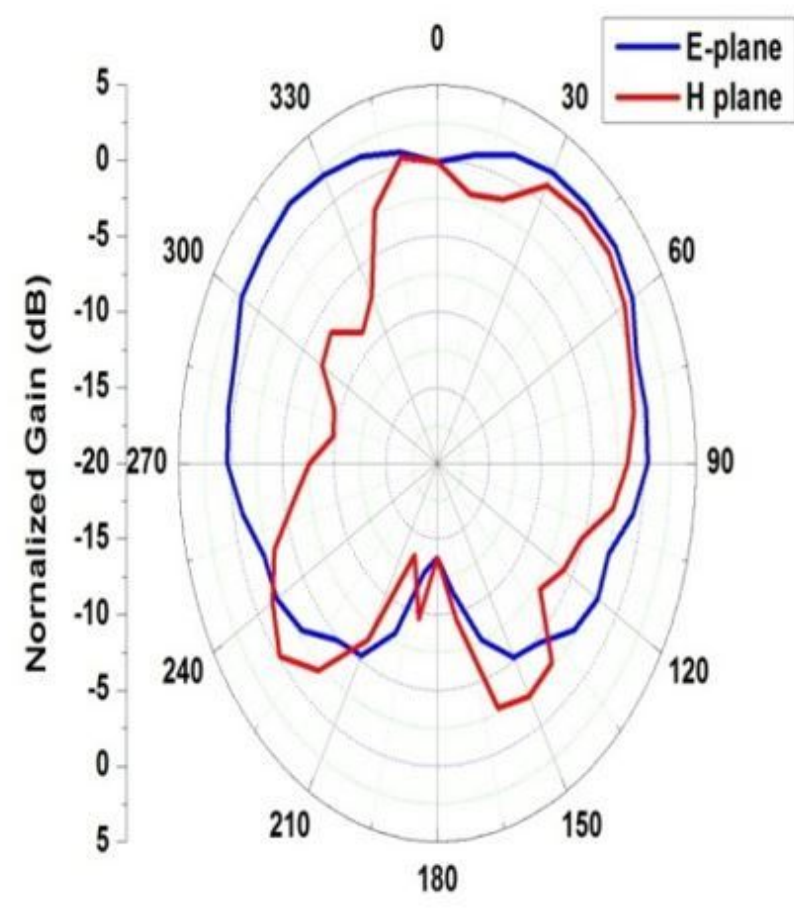

(a)

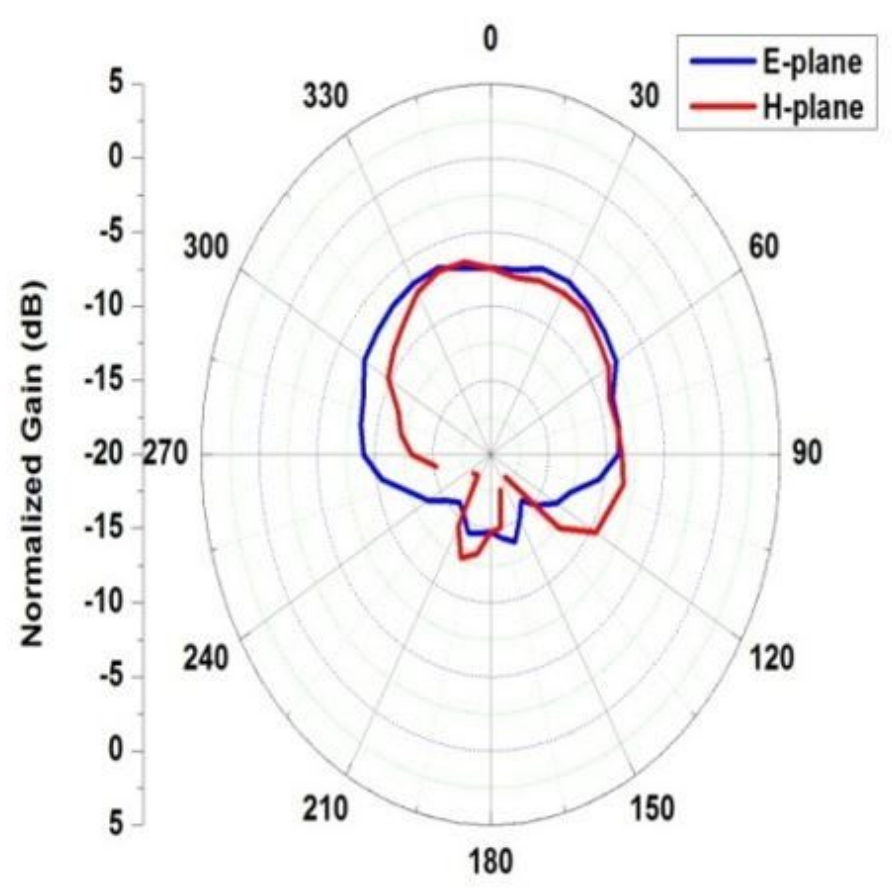

(b)

Figure 8

E-Plane/H-Plane simulated radiation pattern at $10 \mathrm{GHz}$ center frequency (a) using FR4 epoxy substrate (b) using Ga doped ferrite material 


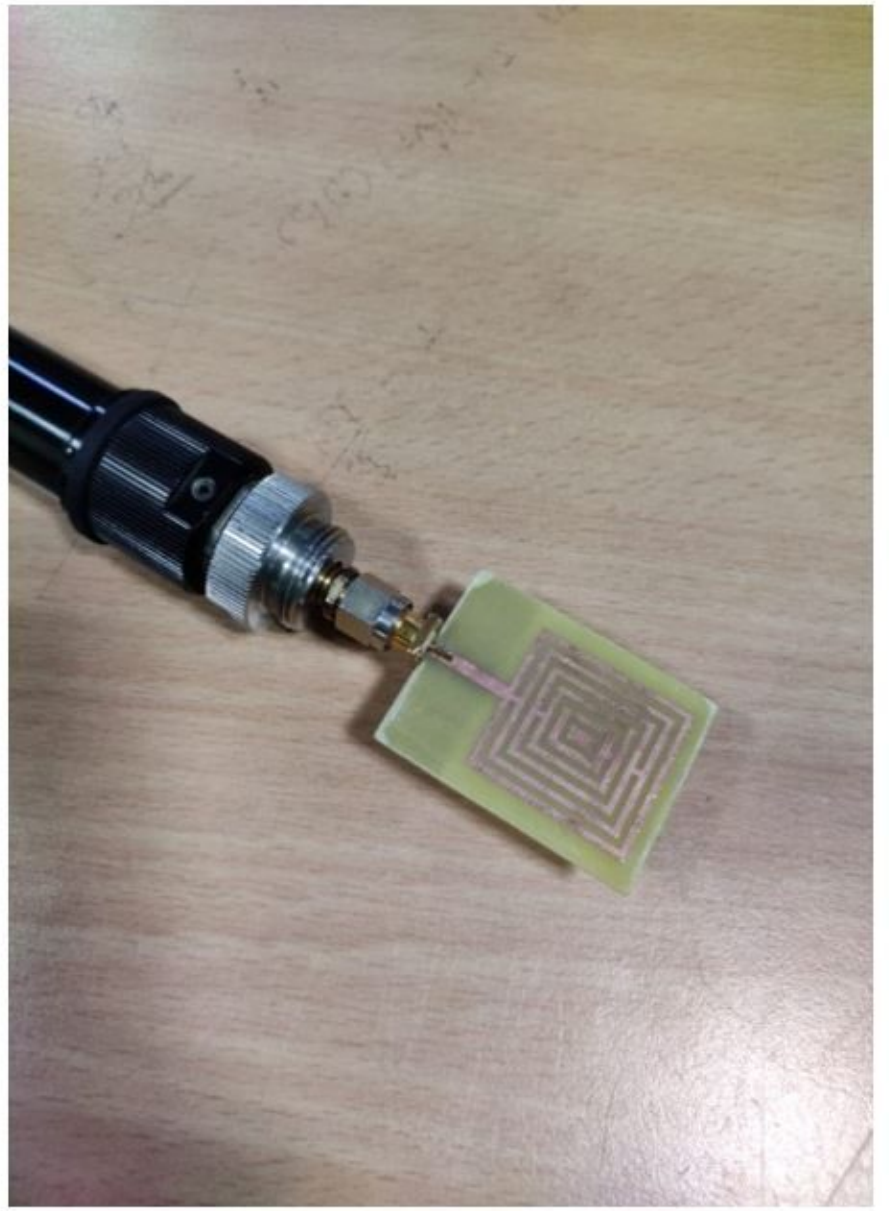

(a)

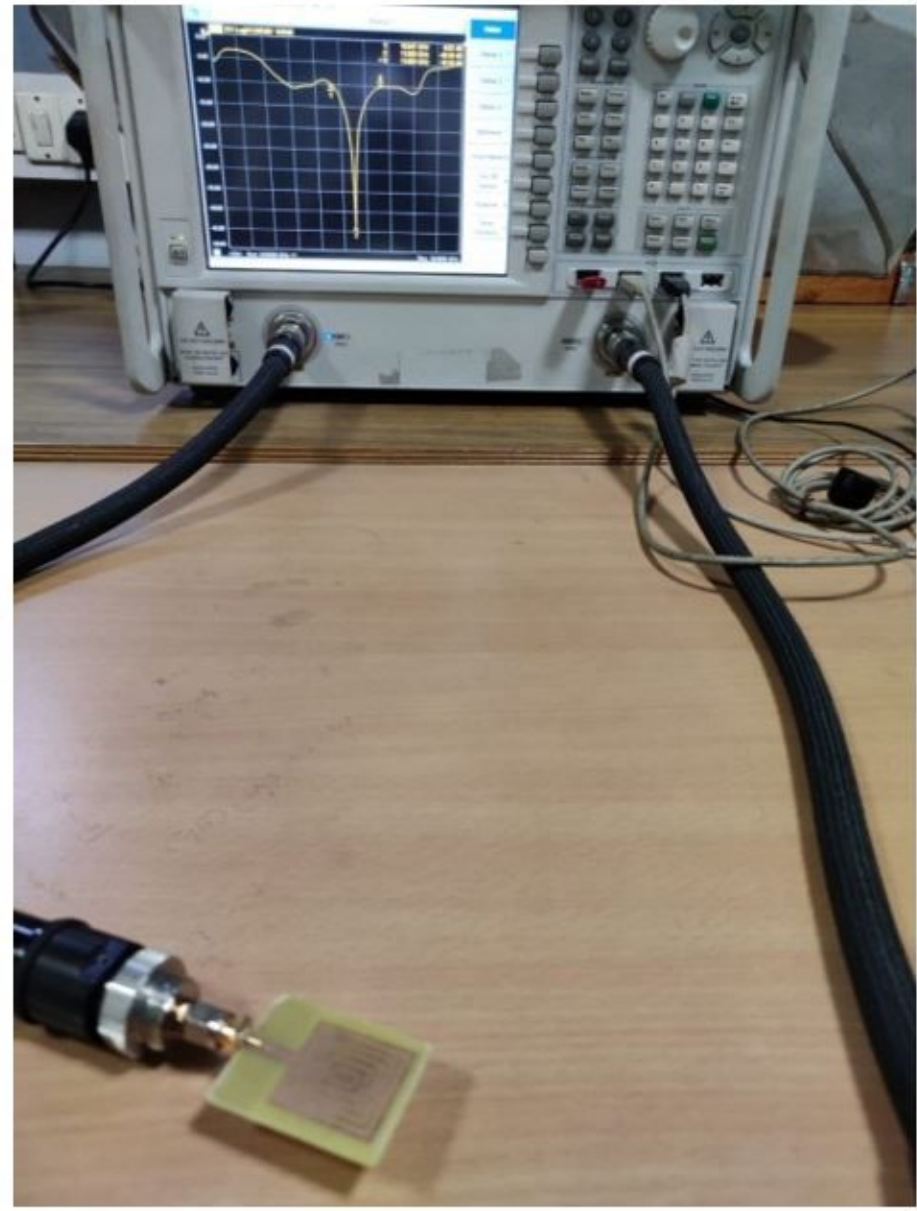

(b)

Figure 9

$(a, b)$ : Fabricated antenna measurement using Vector Network Analyzer 


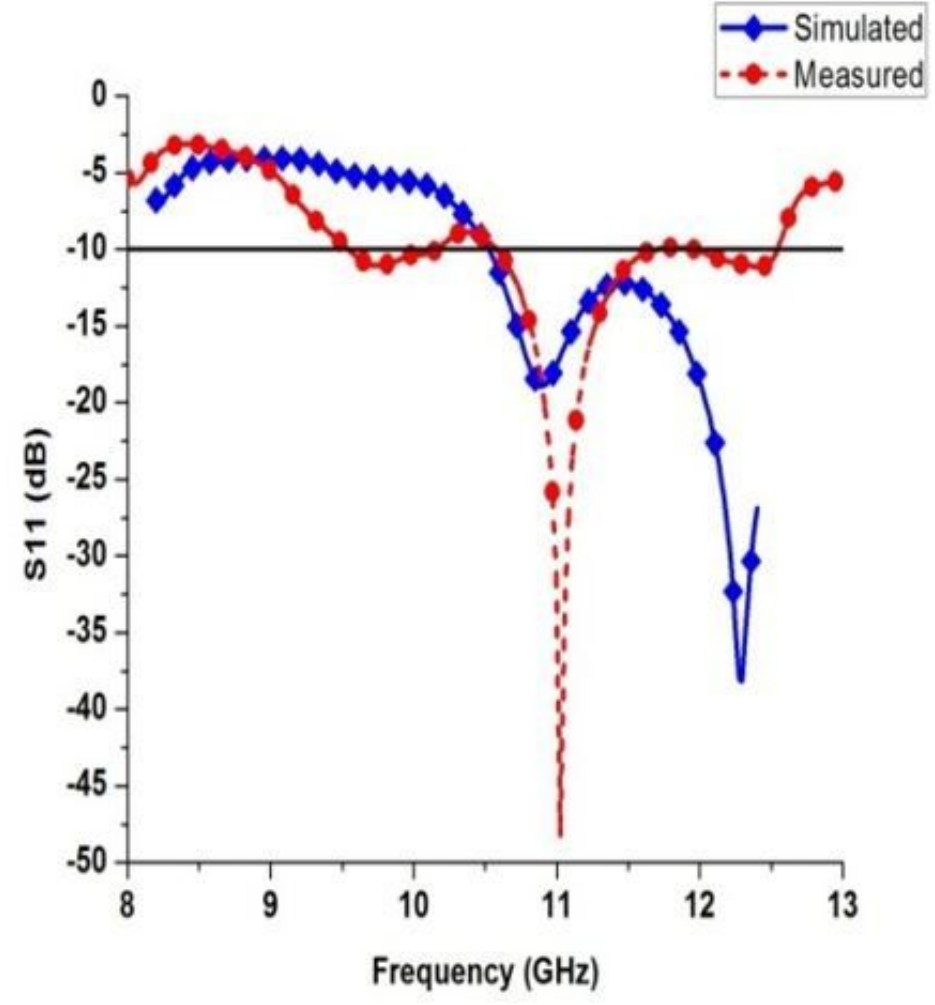

(a)

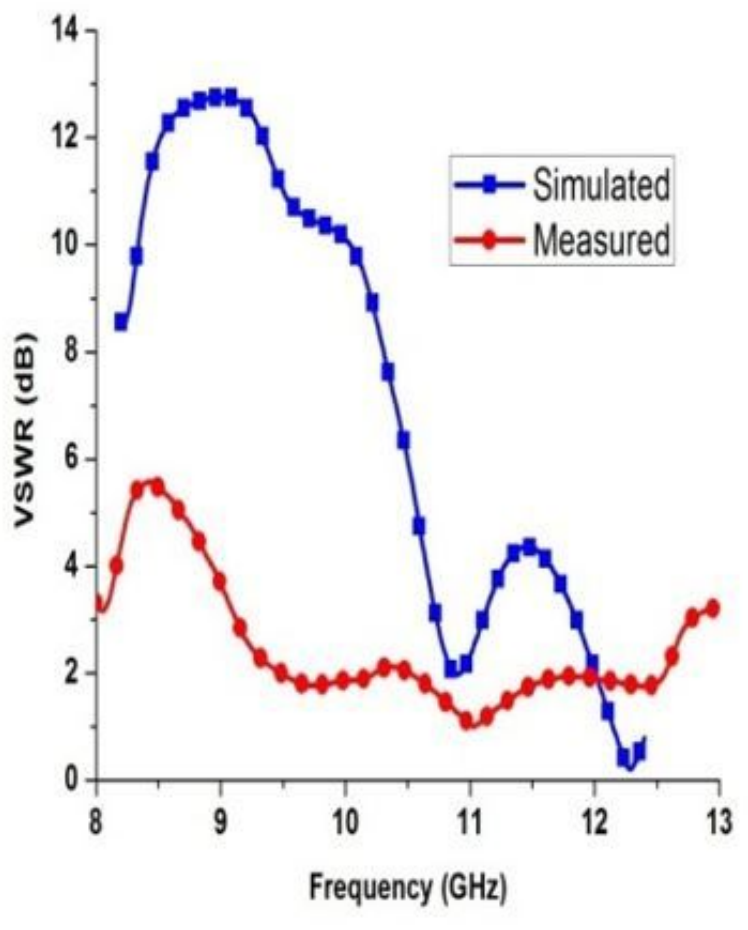

(b)

Figure 10

Comparison of Measured and Simulated results using FR4 epoxy substrate (a) Return loss parameter (b) VSWR 


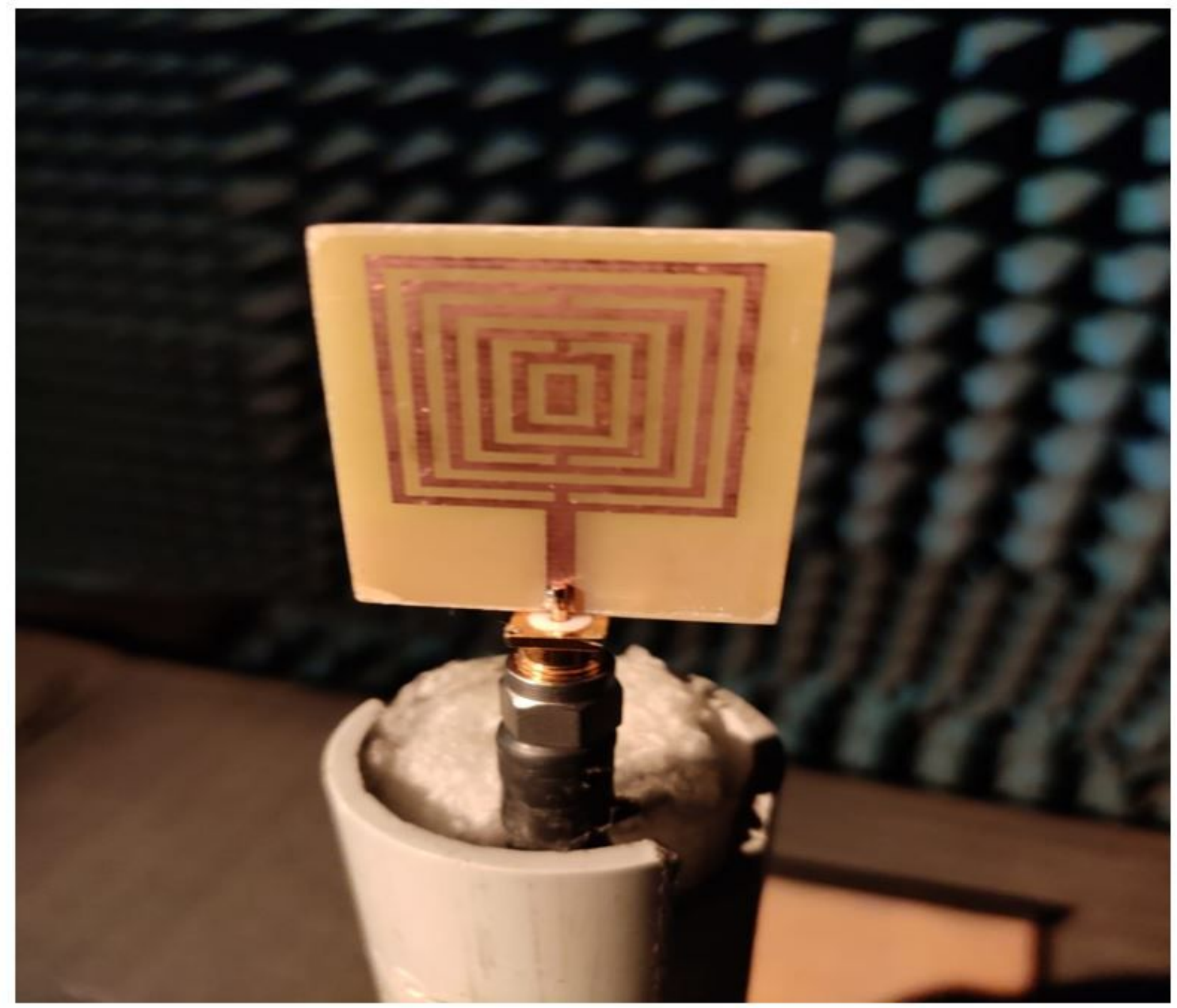

Figure 11

Measurement setup of the fabricated antenna in Anechoic Chamber 


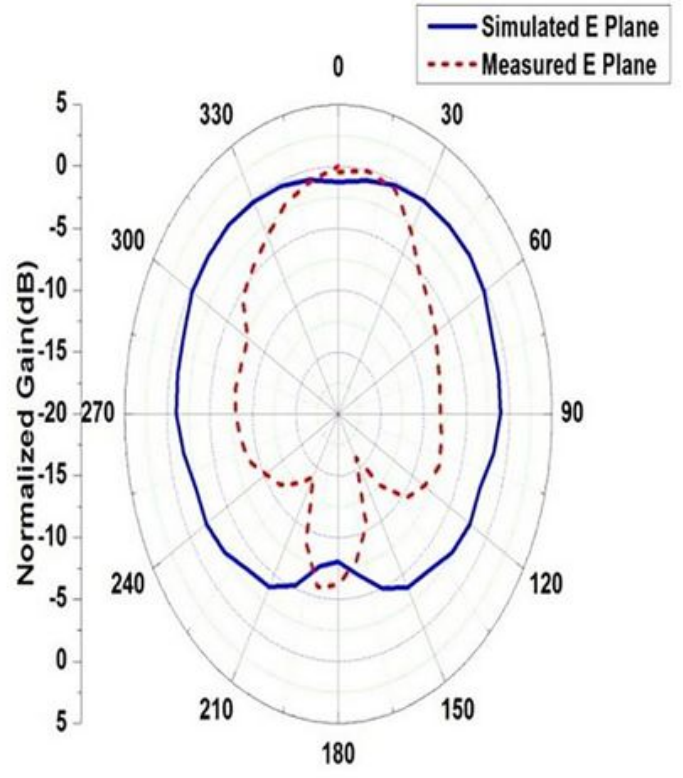

(a)

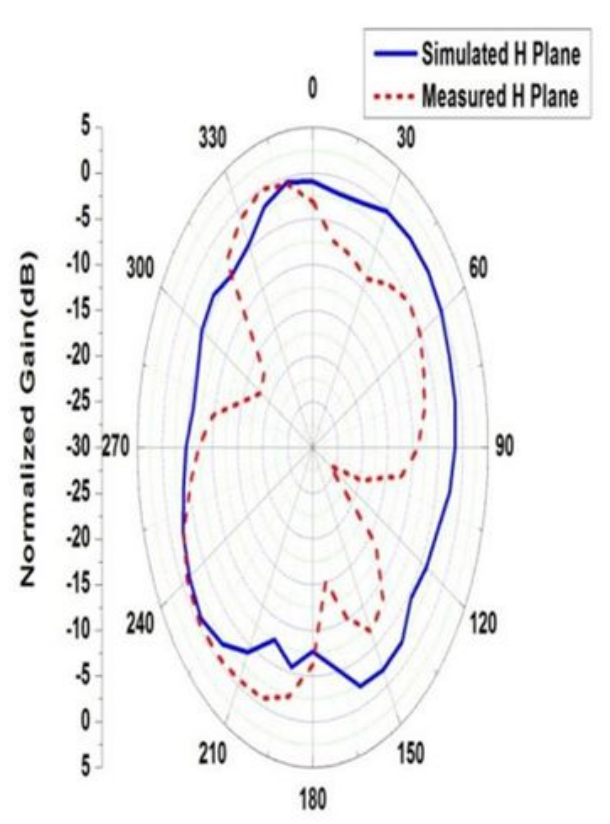

(c)

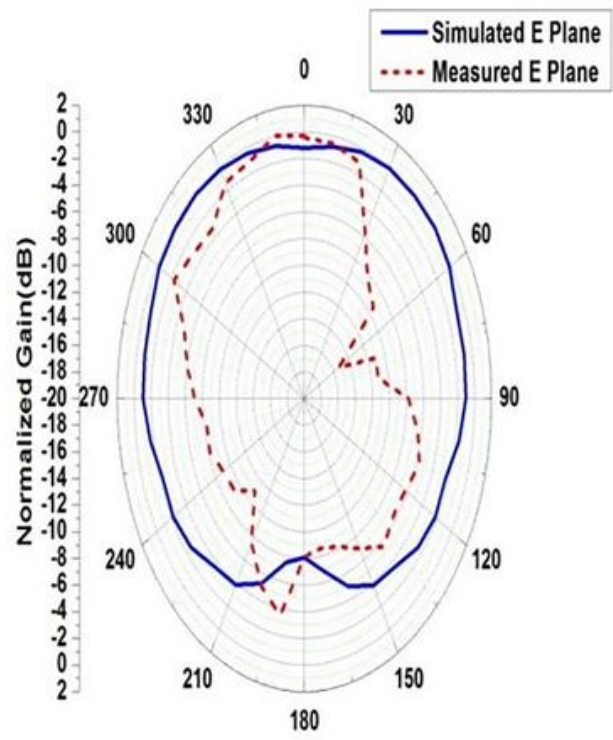

(b)

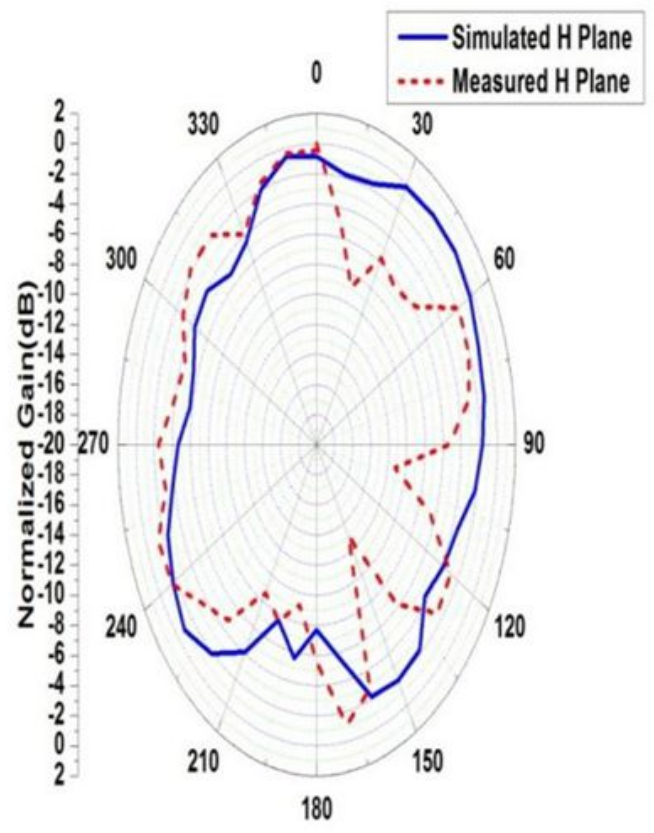

(d)

\section{Figure 12}

Comparison of simulated as well as measured radiation pattern of proposed antenna using FR4 substrate (a) simulated E-plane at $10 \mathrm{GHZ}$ and measured E-Plane at $10.54 \mathrm{GHz}$ (b) simulated E-plane at $10 \mathrm{GHZ}$ and measured E-Plane at $11.98 \mathrm{GHz}$ (c) simulated $\mathrm{H}$-plane at $10 \mathrm{GHZ}$ and measured $\mathrm{H}$-Plane at $10.54 \mathrm{GHz}(\mathrm{d})$ simulated $\mathrm{H}$-plane at $10 \mathrm{GHZ}$ and measured $\mathrm{H}$-Plane at $11.98 \mathrm{GHz}$. 